UNIVERSIDADE DE SÃO PAULO

FACULDADE DE ECONOMIA, ADMINISTRAÇÃO E CONTABILIDADE DE RIBEIRÃO PRETO DEPARTAMENTO DE ECONOMIA

PROGRAMA DE PÓS-GRADUAÇÃO EM ECONOMIA - ÁREA: ECONOMIA APLICADA

\title{
O impacto da escolaridade da população sobre a pobreza e a desigualdade de renda no Brasil: 1993-2011
}

\author{
PAULA PENKO TEIXEIRA
}

Orientadora : Prof. ${ }^{a}$ Dr. ${ }^{a}$ Elaine Toldo Pazello

Ribeirão Preto

2015 
Prof. Dr. Marco Antonio Zago

Reitor da Universidade de São Paulo

Prof. Dr. Sigismundo Bialoskorski Neto

Diretor da Faculdade de Economia, Administração e Contabilidade de Ribeirão Preto

Prof. Dr. Sérgio Kannebley Júnior

Chefe do Departamento de Economia

Prof. Dr. Cláudio Ribeiro de Lucinda

Coordenador do Programa de Pós-Graduação em Economia Aplicada 


\title{
PAULA PENKO TEIXEIRA
}

\section{O impacto da escolaridade da população sobre a pobreza e a desigualdade de renda no Brasil: 1993-2011}

\author{
Dissertação de Mestrado submetida ao Pro- \\ grama de Pós-Graduação em Economia - Área: \\ Economia Aplicada da Faculdade de Econo- \\ mia, Administração e Contabilidade de Ri- \\ beirão Preto da Universidade de São Paulo, \\ para obtenção do título de Mestre em Ciências. \\ Versão corrigida. A original encontra-se dis- \\ ponível na FEA-RP/USP.
}

PAULA PENKO TEIXEIRA

Orientadora Prof. ${ }^{\text {a }}$ Dr. ${ }^{\text {a }}$ Elaine Toldo Pazello

Ribeirão Preto

2015 
AUTORIZO A REPRODUÇÃO E DIVULGAÇÃO TOTAL OU PARCIAL DESTE TRABALHO, POR QUALQUER MEIO CONVENCIONAL OU ELETRÔNICO, PARA FINS DE ESTUDO E PESQUISA, DESDE QUE CITADA A FONTE.

\section{FICHA CATALOGRÁFICA}

Teixeira, Paula Penko

O impacto da escolaridade da população sobre a pobreza e a desigualdade de renda no Brasil: 1993-2011. Ribeirão Preto, 2015.

88 p. : il. $30 \mathrm{~cm}$

Dissertação de Mestrado, apresentada à Faculdade de Economia, Administração e Contabilidade de Ribeirão Preto/ USP.

Orientadora: Pazello, Elaine Toldo.

1. Pobreza 2. Desigualdade 3. Educação 4. Decomposição 5. Micro-simulações 


\section{Folha de Aprovação}

Nome: TEIXEIRA, Paula Penko

Título: O impacto da escolaridade da população sobre a pobreza e a desigualdade de renda no Brasil: 1993-2011.

Dissertação de Mestrado submetida ao Programa de Pós-Graduação em Economia - Área: Economia Aplicada da Faculdade de Economia, Administração e Contabilidade de Ribeirão Preto da Universidade de São Paulo, para obtenção do título de Mestre em Ciências. Versão corrigida. A original encontra-se disponível na FEA-RP/USP.

Aprovada em:

BANCA EXAMINADORA

Prof. Dr.

Instituição:

Assinatura:

Prof. Dr.

Instituição: Assinatura:

Prof. Dr. Instituição: Assinatura: 
Dedico esta dissertação aos meus pais, Manoel e Hozana. 


\section{Agradecimentos}

Primeiramente, agradeço à Deus, por estar presente em todas as etapas da minha vida. Fazendo-me acreditar em algo maior e guiando-me.

Agradeço ao meu pai, Manoel. Por todas as palavras de conselho e consolo. Pelo apoio. Por acreditar, mesmo quando eu já não acreditava.

Agradeço à minha mãe, Hozana. Por todos os ensinamentos, pelo exemplo de mulher.

Agradeço aos meus irmãos, Caio e Bruna, pelo companheirismo e pelas inúmeras conversas. Por estarem por perto.

Agradeço ao Felipe, por todo o carinho, amor e dedicação a mim reservados. Pelos sonhos compartilhados.

Agradeço à minha orientadora e amiga, Elaine, por tudo o que me foi ensinado, pela paciência e tempo a mim dedicados.

Agradeço aos meus amigos, que estiveram presentes durante esta jornada, apoiando-me cada um à sua maneira.

Mais uma vez, agradeço à Deus. 
"Para ser grande, sê inteiro: nada

Teu exagera ou exclui. Sê todo em cada coisa. Põe quanto és No mínimo que fazes. Assim em cada lago a lua toda Brilha, porque alta vive". 
TEIXEIRA, P. P. O impacto da escolaridade da população sobre a pobreza e a desigualdade de renda no Brasil: 1993-2011. 2015. 88p. Dissertação (Mestrado) - Faculdade de Economia, Administração e Contabilidade de Ribeirão Preto, Universidade de São Paulo, Ribeirão Preto, 2015.

\section{Resumo}

O tema deste trabalho compreende o estudo do impacto da educação no nível da renda e sua respectiva distribuição no Brasil ao longo dos anos (1993 a 2011). A metodologia adotada no estudo é um modelo de decomposição microeconométrica com simulações, no qual conseguimos avaliar o impacto da escolaridade sobre a pobreza e a desigualdade de renda. Destacamos dois principais resultados. Na simulação do efeito quantidade, temos que a educação explica $34 \%$ da queda no indicador de proporção de pobres entre 1993 e 2011, 43\% da queda na proporção de extremamente pobres e $13 \%$ da queda no Gini (desigualdade de renda) no mesmo período. Para os anos entre 2001 e 2011, o efeito quantidade da educação explica $27 \%$ da queda na proporção de pobres e de extremamente pobres e apenas $1 \%$ da queda na desigualdade de renda ocorrida no período analisado. Já na simulação do efeito preço da educação, o impacto se mostrou relevante somente na queda na desigualdade de renda: a educação explica $15 \%$ da queda observada entre 1993 e 2011 e 33\% da queda ocorrida entre 2001 e 2011.

Palavras-Chave: pobreza, desigualdade, educação, decomposição e micro-simulações.

JEL: I24; I32; O15. 


\title{
TEIXEIRA, P. P. The impact of education of the population on poverty and income
}

inequality in Brazil: 1993-2011. 2015. 88p. Thesis (MPhil) - Graduate School of Economics, Business and Accounting, University of São Paulo, Ribeirão Preto, 2015.

\begin{abstract}
The subject of this work is the impact of education on the level of income and its respective distribution in Brazil over the years (1993-2011). The methodology used in the study is a model of microeconometric decomposition with simulations in which we can isolate the impact of education on poverty and income inequality. We can highlight two main results. In the simulation of the quantity effect, we have concluded that education explains 34\% of the fall in the headcount index between the years 1993 and $2011,43 \%$ of the fall in the headcount index using an indigence line and $13 \%$ of the fall in the Gini indicator (income inequality) in the same period . For the years between 2001 and 2011, the quantity effect of education explains $27 \%$ of the fall in the headcount index (using both poverty and indigence lines) and only $1 \%$ of the fall in income inequality that happened during the period. In the simulation of the price effect of education, the impact was also relevant but only in the fall in income inequality: education explains $15 \%$ of the fall observed between 1993 and 2011 and $33 \%$ of the fall that has occurred between 2001 and 2011.
\end{abstract}

Keywords: poverty, inequality, education, decomposition, microsimulation.

JEL codes: I24; I32; O15. 


\section{Lista de tabelas}

Tabela 1 - Número de observações na amostra . . . . . . . . . . . . . . . . . . . . . 34

Tabela 2 - Número de moradores por domicílio (porcentagem) . . . . . . . . . . . . 35

Tabela 3 - Localização do domicílio (porcentagem) . . . . . . . . . . . . . . . . . . 35

Tabela 4 - Características do domicílio (porcentagem) . . . . . . . . . . . . . . . . 36

Tabela 5 - Faixa etária da população (porcentagem) . . . . . . . . . . . . . . . 37

Tabela 6 - Gênero da população (porcentagem) . . . . . . . . . . . . . . . . . . 37

Tabela 7 - Nível de escolaridade da população (porcentagem) . . . . . . . . . . . . . 38

Tabela 8 - Renda do domicílio líquida da renda da mulher (média mensal em $\mathrm{R} \$$ de 2012) . . . . . . . . . . . . . . . . . . . . 39

Tabela 9 - População Economicamente Ativa (porcentagem) . . . . . . . . . . . . . 40

Tabela 10 -Condição do emprego (porcentagem) . . . . . . . . . . . . . . . . . . . 41

Tabela 11 -Renda (média mensal em $\mathrm{R} \$$ de 2012) . . . . . . . . . . . . . . . . . . . 42

Tabela 12 -Renda de não-trabalho . . . . . . . . . . . . . . . . . . . . 43

Tabela 13 -Indicadores de pobreza e de desigualdade de renda . . . . . . . . . . . . 44

Tabela 14 -Equação de rendimentos: Regressão* para Trabalhadores Formais . . . . 48

Tabela 15 -Equação de rendimentos: Regressão* para Trabalhadores Informais . . . 49

Tabela 16 -Equação de rendimentos: Regressão* para Autônomos/Empregadores . 50

Tabela 17 -Efeito marginal das variáveis sobre a participação no mercado de trabalho (chefe de família) . . . . . . . . . . . . . . . . . . . . . . 55

Tabela 18 -Efeito marginal das variáveis sobre a participação no mercado de trabalho (de-

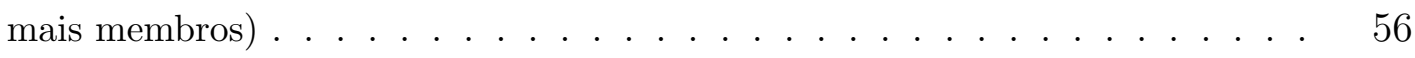

Tabela 19 - Média de anos de estudo - observada e após simulações (a partir da imposição da distribuição da variável em 2011) . . . . . . . . . . . . . . . . 60

Tabela 20 -Escolha ocupacional (\%) - observada e após simulações (a partir da imposição da distribuição da variável em 2011)] . . . . . . . . . . . . . . . . 60

Tabela 21 -Escolha ocupacional (valores absolutos) - observada e após simulações (a partir da imposição da distribuição da variável em 2011) . . . . . . . . . . 61

Tabela 22 - Renda média do trabalho - observada e após simulações (a partir da imposição da distribuição da variável em 2011) . . . . . . . . . . . . . . . . 62

Tabela 23 -Quartis da renda do trabalho - observados e após simulações (a partir da imposição da distribuição da variável em 2011) . . . . . . . . . . . . . . 63

Tabela 24 - Indicadores de pobreza e desigualdade - observados e após simulações (a partir da imposição da distribuição da variável em 2011) . . . . . . . . . 64 
Tabela 25 -Renda média do trabalho - observada e após simulações (em 1993 e 2001, usando os coeficientes da educação de 2011) . . . . . . . . . . . . . . . . 67

Tabela 26 -Quartis da renda do trabalho - observados e após simulações (em 1993 e 2001, usando os coeficientes da educação de 2011) . . . . . . . . . . . . . 67

Tabela 27 - Indicadores de pobreza e desigualdade - observados e após simulações (em 1993 e 2001, usando os coeficientes da educação de 2011) . . . . . . . . . 68 


\section{Lista de ilustrações}

Figura 1 - Efeito marginal da educação na formação da renda (homens) . . . . . . . 51

Figura 2 - Efeito marginal da educação na formação da renda (mulheres) . . . . . . 52

Figura 3 - Efeito marginal da educação na participação no mercado de trabalho (chefes) 57

Figura 4 - Efeito marginal da educação na participação no mercado de trabalho (demais membros 


\section{Sumário}

Lista de tabelas . . . . . . . . . . . . . . . . . . . . . . . . . 11

Lista de ilustrações . . . . . . . . . . . . . . . . . . . . . . . . . . 13

Sumário . . . . . . . . . . . . . . . . . . . . . . . . . . . 14

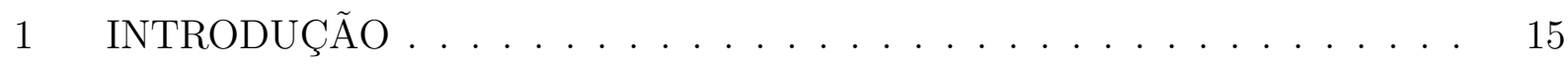

$2 \quad$ REVISÃO BIBLIOGRÁFICA $\ldots \ldots \ldots \ldots \ldots \ldots$

$3 \quad$ METODOLOGIA . . . . . . . . . . . . . . . . . . . . . . 23

3.1 Primeira etapa - equação da renda domiciliar $\ldots \ldots \ldots$. . . . . . 23

3.2 Segunda etapa - equação de participação . . . . . . . . . . . . . . 24

3.3 Terceira etapa - equação de rendimento individual . . . . . . . . . . . 26

$3.4 \quad$ Quarta etapa - simulações $\ldots \ldots \ldots \ldots$

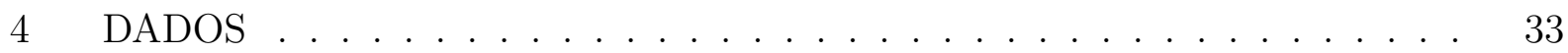

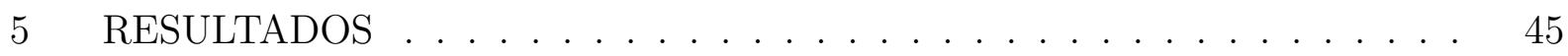

$5.1 \quad$ Resultados das estimações $\ldots \ldots \ldots \ldots$. . . . . . . . . . . 45

$5.2 \quad$ Resultados das simulações $\ldots \ldots \ldots$

$5.2 .1 \quad$ Efeito quantidade da educação $\ldots \ldots \ldots \ldots$

5.2 .2 Efeito preço da educação $\ldots \ldots \ldots \ldots \ldots$

5.2 .3 Resumo das simulações . . . . . . . . . . . . . . . 70

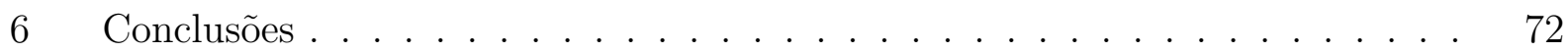

Referências . . . . . . . . . . . . . . . . . . . . 74

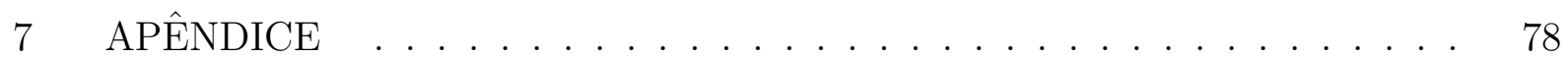

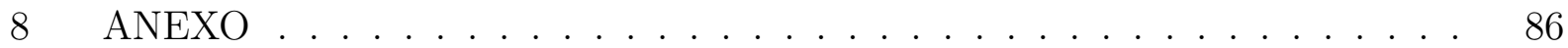




\section{INTRODUÇÃO}

O tema deste trabalho compreende o estudo do impacto da educação na distribuição da renda no Brasil. A principal motivação deste estudo está em estabelecer qual foi o papel da educação na queda da pobreza e da desigualdade de renda que ocorreu no país nos últimos anos.

No período entre 1993 e 2011, a escolaridade média da população brasileira se elevou: passando de 5,1 anos em 1993, para 6,1 anos em 2001 e chegando a 7,4 anos em 2011. Tendo em vista esse cenário, buscou-se avaliar a influência dessa variação ocorrida na distribuição da educação sobre a renda dos brasileiros.

A proposta de focar na análise da educação e sua influência na formação da renda está baseada na teoria de que a educação tem a capacidade de gerar diferenças de produtividade entre indivíduos que se refletem nos rendimentos dos mesmos e que permanecem ao longo da vida. Além disso, temos que a "educação afeta mais rendimentos de trabalho do que outros rendimentos no Brasil" [Lisboa e Menezes-Filho 2001], o que é muito significativo considerando que rendimentos provenientes do trabalho são a maior fonte de renda da população.

Temos assim que, o nível de estudo da população afeta diretamente o nível de pobreza e de desigualdade de renda. Considerando os efeitos diretos da educação, identificamos dois efeitos: efeito quantidade (relativo à variação no número de anos de estudo do indivíduo) e efeito-preço (relativo à variação na forma com que se remunera a educação). Ou seja, com o efeito quantidade espera-se que aumentar os anos de estudo de um indivíduo, eleve sua renda. Já o efeito-preço se refere ao valor marginal da educação: se esse preço se eleva, mesmo sem variação positiva nos anos de estudo do indivíduo, espera-se um aumento na renda. Desta forma, buscamos avaliar qual foi o efeito-preço e o efeito-quantidade da educação sobre a pobreza e a desigualdade de renda no Brasil. 
A análise será realizada para os anos de 1993, 2001 e 2011, com os dados da Pnad (Pesquisa Nacional por Amostra de Domicílios) disponibilizada pelo IBGE (Instituto Brasileiro de Geografia e Estatística).

Segundo os dados (que serão apresentados na estatística descritiva deste trabalho), temos que a proporção de pobres no Brasil caiu de 42,8\% em 1993 para 18,4\% em 2011, enquanto que a desigualdade de renda (medida pelo índice de Gini) que era de 0,607 em 1993, passou para 0,596 em 2001 e por fim, para 0,540 em 2011. Assim, embora tenha havido uma melhora significativa recente nos indicadores de pobreza e de distribuição de renda para o Brasil, seus níveis ainda são muito elevados, reforçando a importância deste estudo.

Segundo relatório do programa das Nações Unidas para o Desenvolvimento (Pnud), em 2011 dos 15 países do mundo mais desiguais, 10 deles estão na América Latina ou Caribe. Sendo o Brasil, o $3^{0}$ colocado neste ranking, com 0,56 empatando com o Equador. Bolívia, Camarões e Madagascar se encontram com os piores índices (todos empatados com 0,60), seguidos da África do Sul, Tailândia e Haiti (0,59). Países próximos com melhores resultados são: Argentina, Venezuela, Costa Rica e Uruguai, todos com indicadores abaixo de 0,49.

A principal contribuição deste estudo se refere às políticas públicas. Estudar os determinantes da desigualdade de renda no país pode ser de utilidade na esfera das políticas públicas que visam minar os problemas que advém de "um país desigual, exposto ao desafio histórico de enfrentar uma herança de injustiça social, que excluiu parte significativa de sua população do acesso a condições mínimas de dignidade e cidadania" Barros, Henriques e Mendonça 2001.

Sobre a metodologia utilizada, trata-se de um modelo de decomposição microeconométrica com simulações. Alguns estudos aplicando variações da metodologia aqui utilizada já foram realizados, inclusive para o Brasil, em [Ferreira e Barros 1999]. No entanto, este artigo considerou o período de 1976 a 1996, ou seja, não abrange o período de queda recente de desigualdade de renda no país (a partir do final da década de 90). Além disso, a parametrização que propomos aqui é diferente uma vez que consideramos a questão da formalidade do emprego sobre a formação da renda. 
Mais detalhadamente, trata-se de um modelo de formação de renda domiciliar, no qual realizamos duas simulações: a do efeito-quantidade e a do efeito-preço da educação. Assim, na primeira simulação, impomos a distribuição da variável "anos de estudo" de 2011 em 1993 e em 2001, e avaliamos o quanto essa mudança altera a renda do indivíduo e posteriormente a renda domiciliar, que por fim, resulta em variações nos indicadores de pobreza e desigualdade. Ou seja, queremos responder à seguinte pergunta: se a população apresentasse em 1993 (ou 2001), a mesma distribuição dos anos de estudo observada em 2011, o que aconteceria com os indicadores de pobreza/desigualdade de 1993 (e de 2001)?

Na segunda simulação (efeito-preço) substituímos os parâmetros estimados para a educação nas equações de rendimento (de 2011 em 1993 e em 2001) e avaliamos como isso afeta os rendimentos e por último, os indicadores de pobreza e desigualdade de renda. Ou seja, queremos saber: se em 1993 (ou em 2001), a educação fosse remunerada/premiada da mesma forma que em 2011, quais seriam as alterações esperadas nos indicadores de pobreza e de desigualdade de renda de 1993 (e de 2001)?

Destacamos dois principais resultados. Primeiro, na simulação do efeito quantidade, temos que a educação explica 34\% da queda no indicador de proporção de pobres entre 1993 e 2011, 43\% da queda na proporção de extremamente pobres e 13\% da queda no Gini (desigualdade de renda) no mesmo período. Para os anos entre 2001 e 2011, o efeito quantidade da educação explica $27 \%$ da queda na proporção de pobres e de extremamente pobres e apenas 1\% da queda na desigualdade de renda ocorrida no período analisado.

Segundo, na simulação do efeito preço da educação, o impacto se mostrou relevante somente na queda na desigualdade de renda: a educação explica $15 \%$ da queda observada entre 1993 e 2011 e $33 \%$ da queda ocorrida entre 2001 e 2011.

Por fim, o presente trabalho está dividido em 5 seções, além desta introdução. A segunda seção apresenta uma revisão da literatura, a terceira seção descreve a metodologia a ser utilizada, a quarta seção mostra os dados da amostra, a quinta seção apresenta os resultados e na sexta e última seção, conclui-se o estudo. 


\section{REVISÃO BIBLIOGRÁFICA}

Apresentamos, a seguir, alguns resultados para a América Latina (com destaque para o Brasil), uma vez que se tratam de países, em sua maioria, menos desenvolvidos e nos quais a desigualdade de renda e a pobreza são fenômenos mais frequentes.

Em [Vélez et al. 2005], estuda-se a evolução da desigualdade de renda na Colômbia entre os anos de 1978 a 1995 e apontam o aumento da escolaridade da força de trabalho como sendo de grande importância na questão da desigualdade, mas atuando de maneira a acentuá-la. Este resultado expressa a complexidade que envolve a relação da educação com a renda, uma vez que o aumento do nível de escolaridade pode acentuar ou reduzir a situação de pobreza e de desigualdade de renda em um país, dependendo de como ocorre este acréscimo nos anos de estudo, de forma homogênea ou mais restrita a uma parcela da população, por exemplo.

Ainda sobre a América Latina, temos análises para a Argentina e o México apresentados no livro Bourguignon, Lustig et al. 2005. Para a Argentina, analisa-se a desigualdade de renda no período compreendido entre 1986 e 1998. Os autores apontam que a partir de 1992 há um aumento nos indicadores de desigualdade decorrente do aumento no retorno da educação, além da queda no número de horas trabalhadas. Já no México, temos que o aumento na desigualdade de renda, que ocorre entre 1984 e 1994 no país, é em grande parte explicado pela educação. Segundo os autores, mudanças no efeito preço e quantidade da educação foram responsáveis por dois quintos do aumento da desigualdade.

Os artigos anteriores aplicam uma metodologia semelhante a que será adotada neste presente trabalho, o mesmo acontece em [Fields e Soares 2004]. Este estudo analisa a distribuição de renda da Malásia para os anos de 1984 até 1997. Os principais resultados inferem que a educação não se destaca no processo de aumento da desigualdade que ocorre no período, e sim, fatores como o acúmulo do capital físico e mudanças institucionais e tecnológicas. 
Considerando a literatura nacional sobre o tema, apresentamos inicialmente o artigo [Langoni 1974. Este artigo é considerado o mais provável introdutor da utilização de microdados para estudos econômicos no Brasil, introduzindo na literatura brasileira de microeconomia aplicada a metodologia na qual se realizam simulações a partir de regressões econométricas.

O objetivo do estudo anterior era analisar a distribuição de renda no país para os anos de 1960 e 1970, utilizando-se uma regressão log-linear para estimar o efeito das variáveis (educação, idade, sexo, região e atividade realizada) que afetam a renda do indivíduo. Como principais resultados, o artigo destaca o papel da educação e como este se mostrou heterogêneo em termos de setor da atividade e região. O autor diz que: "Quando passamos para um ambiente econômico mais dinâmico e sofisticado, $[\ldots]$ o nível de educação [e não o capital físico] é que passa a ser a condição necessária para garantir altos níveis de renda." Ainda afirma que, a desigualdade no período foi substancial para o setor urbano, e principalmente, nas atividades mais modernas, onde há maior uso de mão-de-obra qualificada.

Para o período de 1976 a 1986, temos o artigo [Reis e Barros 1991], que analisa especificamente a educação impactando a desigualdade de renda salarial no Brasil. O estudo considera a educação como único determinante da renda e restringe a pesquisa para nove regiões metropolitanas, excluindo da amostra pessoas que não trabalham. Analisa-se, assim, o índice de Theil para capturar possíveis impactos da educação sobre a renda individual. Entre os resultados, destacamos: a desigualdade de renda se mostrou maior em regiões mais pobres e menos desenvolvidas (no caso, as regiões metropolitanas do Norte e Nordeste) e menor em regiões mais desenvolvidas (São Paulo, Curitiba e Porto Alegre). A explicação seria de que as regiões metropolitanas mais desenvolvidas são menos desiguais, não porque apresentam maiores níveis de educação ou melhor distribuição da educação, mas sim, devido a uma relação menos acentuada entre salário e educação. 
Em [Menezes-Filho 2001], temos um estudo que propõe algo muito semelhante ao objetivo deste trabalho: avaliar os impactos da evolução da escolaridade da população brasileira sobre o mercado de trabalho. O artigo abrange os anos de 1977 a 1997, ou seja, ainda uma fase de elevada desigualdade de renda no Brasil. Entre os resultados destacados pelo artigo anterior, temos que "se eliminássemos todos os diferenciais salariais associados aos diferentes níveis educacionais, a desigualdade salarial em 1977 cairia em 50\%”. Já para o ano de 1997, concluem que a desigualdade salarial se reduz em comparação com 1977, no entanto, a desigualdade descontada dos efeitos da educação permaneceu constante, sugerindo portanto que houve "uma queda na desigualdade associada à educação nestes 20 anos".

Já no trabalho que nos foi base para a adoção da metodologia, vemos resultados interessantes para o Brasil em um período muito semelhante ao do artigo anterior (entre 1976 e 1996). Em [Ferreira e Barros 1999], os autores se perguntam porque a taxa de indigência do país se eleva no período, enquanto que a renda média e a desigualdade se mantêm praticamente estáveis. Como resposta, apontam-se as mudanças na estrutura ocupacional (elevação do desemprego e da informalidade) e o declínio no retorno médio da educação e da experiência como principais fatores para explicação da questão abordada no artigo (aumento da indigência mantendo desigualdade de renda constante).

No artigo Barros, Corseuil e Leite 1999, temos uma análise da pobreza no Brasil para o ano de 1995 utilizando dados da Pnad e por meio de métodos de decomposição econométrica e simulações, assim como neste presente trabalho. O estudo objetivou mostrar o quanto a pobreza está relacionada com as imperfeições existentes no mercado de trabalho brasileiro: segmentação, discriminação e desemprego. Segundo os autores, a principal conclusão do artigo é a de que: "independent of the indicator chosen, elimination of the unemployment, underemployment and discrimination in the labor market would have a relatively limited effect on poverty". 
Assim como no estudo anterior, Barros, Franco e Mendonça 2007 também analisam os determinantes da renda com foco na relação da renda com as imperfeições do mercado de trabalho. O objetivo foi produzir resultados relacionando a pobreza e a desigualdade de renda com fatores de discriminação e de segmentação no mercado de trabalho, comparando os anos de 2001 e 2005. As principais conclusões foram: entre todas as categorias de discriminação (por gênero e cor) e de segmentação (espacial, setorial e entre os segmentos formal e informal), "com exceção da segmentação entre os segmentos formal e informal, todas as demais formas de discriminação e de segmentação declinaram ao longo da década e, em particular, ao longo do último quadriênio". Segundo os autores, a redução nas imperfeições do mercado de trabalho foi fundamental para explicar a queda na desigualdade.

No livro Barros, Foguel e Ulyssea 2006, analisa-se o período mais recente de queda da desigualdade no Brasil. No capítulo referente à relação da educação com a desigualdade de renda, Menezes-Filho, Fernandes e Pichetti 2007], utilizando dados da Pnad para o período de 1981 a 2004, os autores agruparam os dados em células - de acordo com a educação e idade das pessoas - e aplicaram regressões quantílicas a uma especificação que continha idade, tendência e efeitos macroeconômicos. O objetivo era "modelar a evolução de rendimentos em cada grupo educacional" e assim, capturar o efeito da educação sobre a desigualdade de renda: "diferenças nos parâmetros para o mesmo quantil entre grupos educacionais medem mudanças nos retornos à educação em pontos específicos da distribuição".

Nas simulações, os autores identificam dois efeitos principais: compressão - quando a estrutura populacional daquele ano se mantém e os rendimentos variam - e composição no qual ocorre o inverso. A principal conclusão é a de que: anteriormente "enquanto o efeito composição agia no sentido de aumentar a desigualdade, o efeito compressão [o efeito compressão está relacionado ao declínio nos retornos da escolarização] atuava no sentido de reduzí-la. A partir de 1997, com o rápido aumento da proporção de jovens no ensino médio, os dois efeitos passaram a atuar na mesma direção, e o efeito preço começou a atuar com mais intensidade, o que provocou a queda na desigualdade". 
Em [Barros et al. 2010], o estudo é realizado para o período entre 2001 e 2007 e também busca identificar os principais determinantes da queda recente da desigualdade no Brasil. Parte-se de algumas identidades, chegando-se em: $y=a .(o+u . w)$, onde $y$ é a renda familiar per-capita, a é a proporção de adultos na família, o é a renda não derivada do trabalho por adulto, $u$ é a proporção de adultos ocupados e $w$ é a renda do trabalho por trabalhador. O método utilizado é a simulação de distribuições substituindo cenários de um ano em outro, por exemplo, a porcentagem de adultos de 2007 no ano de 2001. As simulações consideram: distribuição da renda familiar por adulto, porcentagem de adultos e distribuição de renda (derivada ou não derivada do trabalho) por adulto. O resultado que destacamos é que, tanto para a desigualdade quanto para a pobreza, os fatores mais importantes na melhoria dos indicadores são a renda do trabalho e a renda não-derivada do trabalho.

Nesta seção, procuramos enfatizar a literatura que relaciona pobreza e desigualdade de renda com educação. No entanto, há trabalhos que estão interessados em outros aspectos, que não serão abordados neste presente estudo. Como exemplo, podemos citar os artigos LEONE, MAIA e BALTAR 2010 e Fernandes, Pazello e Felicio 2002, que buscam encontrar o impacto da composição familiar sobre a pobreza no país. Outro exemplo que pode ser citado é o artigo Ney e Hoffmann 2008 que relaciona pobreza e desigualdade de renda ao tipo de atividade econômica desenvolvida (no meio rural, se agrícola ou não-agrícola).

A questão educacional afeta a pobreza e a desigualdade de renda por diversos canais, entre eles: a participação no mercado de trabalho, a formação dos membros da família, migração e fecundidade Bourguignon, Fournier e Gurgand 1979. Novamente, vale ressaltar que apenas focamos na educação como determinante da renda e, por esta razão, somente incluímos em nosso trabalho as vias pelas quais a educação afeta diretamente a distribuição de renda, conscientes de que o papel da educação é de destaque nessa questão, mas não se limita a ela. 


\section{METODOLOGIA}

A metodologia adotada se assemelha à apresentada no livro Bourguignon, Lustig et al. 2005. Trata-se de uma abordagem de decomposição microeconométrica com simulações. A ideia do método é realizar uma análise das mudanças de longo-prazo na distribuição da renda domiciliar (per-capita) de determinada população, tendo em vista as características socioeconômicas e demográficas dos indivíduos.

O livro anteriormente citado compila artigos que se utilizam da metodologia proposta. Cada artigo é aplicado para um país diferente e propõe pequenas alterações ao modelo original. Neste presente estudo nos baseamos mais fortemente no modelo desenvolvido em [Ferreira e Barros 1999], aplicado para o Brasil para os anos de 1976 a 1996. No entanto, propomos algumas mudanças, sendo que a principal delas é a inclusão da questão da (in)formalidade no mercado de trabalho no modelo.

Abaixo, descrevemos a metodologia que foi dividida em quatro etapas.

\subsection{Primeira etapa - equação da renda domiciliar}

Em uma primeira fase, determinamos a equação da renda domiciliar. A renda do domicílio $h$ é formada pela soma da renda de cada um dos indivíduos daquele domicílio. Estes podem receber renda do salário no mercado formal ou informal ou rendimento como autônomo/empregadon! além de outros tipos de rendimentos não derivados do trabalhd²

1 O grupo de autônomos considera autônomos e empregadores.

2 Com relação a estes outros rendimentos (não derivados do trabalho), temos que estes são compostos por: renda proveniente de aposentadoria, pensão, aluguel, doação, poupança e/ou outros, como transferências. $\mathrm{Na}$ base de dados, se os valores não foram declarados, assumimos iguais a zero para não perdermos estas observações. Assim, possivelmente estamos subestimando a renda proveniente destas fontes. 
Importante ressaltar que consideramos as rendas de todos os trabalhos do indivíduo, uma vez que considerar apenas a renda do trabalho principal levaria a uma subestimação da renda do trabalho. No entanto, como era necessário classificar a renda do trabalho em uma das fontes, optou-se por classificar esta renda total como proveniente da mesma fonte da renda principal (que novamente, pode ser do mercado formal, informal ou autônomo/empregador). Segue abaixo a equação de renda domiciliar proposta, onde $n$ é o tamanho do domicílio:

$$
Y_{h}=\sum_{i=1}^{n} W_{i} L_{i}^{W}+\sum_{i=1}^{n} R_{i} L_{i}^{R}+\sum_{i=1}^{n} \Pi_{i} L_{i}^{\Pi}+Y_{0 h}
$$

Onde: $W_{i}=$ salário do indivíduo $i$ no mercado formal

$R_{i}=$ rendimento do indivíduo $i$ no mercado informal

$\Pi_{i}=$ rendimento do indivíduo $i$ proveniente do lucro de sua empresa

$L_{i}^{W}=$ variável dummy (assume valor um quando indivíduo $i$ recebe salário no mercado formal)

$L_{i}^{R}=$ variável dummy (assume valor um quando indivíduo $i$ recebe rendimentos no mercado informal)

$L_{i}^{\Pi}=$ variável dummy (assume valor um quando indivíduo $i$ recebe lucro de sua empresa) $Y_{o h}=$ demais tipos de renda

A equação anterior (11) não será estimada econometricamente. O cálculo da mesma será a partir dos dados dos domicílios e dos parâmetros encontrados posteriormente na segunda e terceira etapas.

\subsection{Segunda etapa - equação de participação}

Na segunda etapa, utilizamos um modelo de participação no mercado de trabalho. A estimação ocorre a partir do modelo logit multinomial. 
Uma vantagem do método aqui descrito é que se trabalha não somente com a parametrização dos rendimentos, mas também com a parametrização da escolha por participar do mercado de trabalho. Desta forma, conseguimos estudar não somente os fatores que determinam a renda, como também os que determinam a participação no mercado de trabalho, que por consequência afetam a renda do domicílio e por fim, impactam a própria distribuição de renda da população, nosso objeto de estudo.

Assumimos que os indivíduos podem não trabalhar (neste caso, inativos ou desempregados), trabalhar recebendo salário no mercado formal (empregado com carteira, militar e funcionário público estatutário), trabalhar recebendo rendimentos no mercado informal (sem carteira) ou trabalhar como autônomo/empregador e receber sua parcela dos lucros.

Destacamos ainda que, no modelo, consideramos de forma diferente a escolha ocupacional para chefes de família e demais membros do domicílio. Assume-se, portanto, que a decisão por participar do mercado de trabalho difere entre os membros do domicílio. Desta forma, as variáveis explicativas consideradas para cada categoria são diferentes, uma vez que assume-se uma sequência na decisão ocupacional do domicílio: em primeiro lugar, o chefe de família e depois, os demais membros (tendo em vista a decisão do chefe.)

As equações logit multinomial são definidas para cada ano (1993, 2001 e 2011) e cada membro da família (se é chefe ou não). Sinteticamente, trata-se de um processo de escolha, que pode ser assim representado:

$$
s=\operatorname{Arg}_{j} \max \left\{U_{j}=Z_{i}^{h} \gamma_{j}+\epsilon, \quad j=(O, W, R, \Pi)\right\}
$$

Onde $Z$ são as variáveis observadas que explicam a escolha ocupacional, $\epsilon$ são as variáveis não-observadas que supomos possuir distribuição aleatória na população e $U$ é a utilidade derivada da escolha ocupacional $j$. A ideia é que o indivíduo escolhe a alternativa $j$ que mais lhe dá utilidade (maximiza a função utilidade (2)), entre as alternativas: não ocupado (O), formal (W), informal (R) e autônomo/empregador (П). 
Resumindo, para o chefe de família, as variáveis a nível individual são: educação, educação ao quadrado, experiência! ${ }^{3}$, experiência ao quadrado e dummies para região urbana e gênero. As variáveis calculadas por domicílio são: número de membros com determinada faixa etária (entre 0 e 13 anos, entre 14 e 65 anos e mais de 65 anos), média de anos de escolaridade e de idade do domicílio e proporção de homens (todas calculadas sem incluir o chefe). Além disso, as últimas três variáveis são calculadas apenas para membros entre 14 e 65 anos de idade (idade ativa). Desta forma, na ausência de membros nesta faixa etária, estas variáveis se tranformariam em missing e perderíamos estas observações. Para evitar esta perda, quando missing, estas variáveis foram zeradas. Por isso, incluímos uma dummy que é igual a 1 quando não existem indivíduos entre 14 e 65 anos de idade no domicílio, de forma a identificar tais domicílios.

Já os demais membros do domicílio tomam a decisão de participar do mercado de trabalho, considerando todas estas mesmas variáveis e também o status ocupacional do chefe de família e seu rendimento: dummy indicando se chefe é autônomo/empregador e outras duas variáveis iguais a renda do chefe, se formal ou informal.

\subsection{Terceira etapa - equação de rendimento individual}

No terceiro passo do processo, definimos as equações de rendimentos dos indivíduos formais, informais e autônomos/empregadores, respectivamente:

$$
\begin{aligned}
& \log W_{i}=X_{i} \beta^{W}+\varepsilon_{i}^{W} \\
& \log R_{i}=X_{i} \beta^{R}+\varepsilon_{i}^{R} \\
& \log \Pi_{i}=X_{i} \beta^{\Pi}+\varepsilon_{i}^{\Pi}
\end{aligned}
$$

3 A variável experiência foi construída da seguinte forma: experiência = idade. 
Onde: $X_{i}=$ variáveis explicativas (educação, experiência e área de localização, que entram na equação como ed, ed ${ }^{2}, \exp , \exp ^{2}$ e urbano)

$$
\begin{aligned}
& \varepsilon_{i}^{J}=\text { termos de erros da equação } J \quad J=W, R e \Pi \\
& \beta^{J}=\text { parâmetros da equação } J \quad J=W, \text { Re } \Pi
\end{aligned}
$$

As três equações (3), (4), (5) serão estimadas por diferentes modelos ${ }^{4}$, Cabe aqui um esclarecimento. Possivelmente, nas três equações anteriores, deve existir correlação entre o termo de erro e o conjunto de variáveis explicativas (podemos pensar, por exemplo, que a motivação do indivíduo resulta em salários maiores e também deve estar correlacionada com a sua escolaridade).

Sem assumir independência dos erros, esta correlação nos demanda a utilização de algum método de correção para viés de seleção. Por esta razão, utilizamos o procedimento de Heckman para realizar a estimação das equações de rendimentos. No entanto, como o viés de seleção é reconhecidamente mais forte no caso das mulheres do que no dos homens, apenas para este primeiro caso, adotaremos tal estratégia (na qual a renda do domicílio líquida da renda da mulher é o instrumento, uma vez que está relacionada com a renda da mulher no mercado de trabalho, mas não está correlacionada com fatores não observados). Para os homens, a estimação será por Mínimos Quadrados Ordinários (MQO).

Com relação à estimação por Heckman para as mulheres, o primeiro estágio (equação de seleção) será calculado para todas as mulheres (utilizando-se do instrumento - renda domiciliar líquida da renda da mulher) e, assim, obteremos a variável razão inversa de Mills para cada mulher. Então, a partir da razão inversa de Mills, calculamos o segundo estágio da estimação (equação principal). Este segundo estágio será estimado (para as mulheres) separadamente para cada setor ocupacional, fornecendo resultados diferenciados para cada mulher trabalhadora (formal, informal ou autônoma/empregadora).

4 É importante ressaltar que neste modelo não estamos considerando nenhum tipo de segmentação no mercado de trabalho relacionada com raça, tamanho da firma ou qualquer outro atributo que não seja o gênero e a região (zona rural ou urbana). 


\subsection{Quarta etapa - simulações}

No quarto e último passo, partimos para a micro-simulação. Das etapas 2 e 3, obtemos os vetores de parâmetros para cada ano: parâmetros $\gamma$ (relativos à escolha ocupacional) e parâmetros $\beta$ (relativos às três equações de rendimentos para homens e para mulheres). A partir destes parâmetros e utilizando os dados observados em nossa base de dados, recuperamos a equação de renda domiciliar (1).

As simulações irão alterar os parâmetros e as variáveis explicativas (neste estudo, a variável escolhida é a educação - anos de estudo), mantendo tudo o mais constante. Assim, as simulações se dividem em dois grupos: efeito preço para geração de renda e efeito populacional/quantidade.

Em primeiro lugar analisaremos a simulação na qual alteramos a distribuição da variável educação entre os anos estudados (efeito populacional). Uma estratégia semelhante a adotada no artigo [Ferreira e Barros 1999] também é utilizada aqui: de forma a conseguir isolar o efeito de uma mudança na distribuição de determinada variável, inicialmente define-se a distribuição desta variável condicional a outras variáveis relevantes. Assim, regredimos:

$$
e d_{i t}=X_{i t} p_{t}+u_{i t}
$$

onde ed é a variável educação, $i$ é o indivíduo, $t$ é o ano (1993 ou 2001) e $u$ é o termo de erro e $\sigma_{t}$, seu desvio padrão. Então, utilizamos as seguintes variáveis explicativas $(X)$ : idade, idade ao quadrado, dummy para gênero e para a área urbana (com constante) $!^{5}$

$5 \quad$ Após alguns testes, verificamos que o melhor modelo (com melhor predição da variável dependente) para estimar tal regressão é binomial negativa, já que educação (anos de estudo) é uma variável de contagem. 
Podemos regredir a mesma equação para o ano $t^{\prime}$ (2011), e assim, encontrar o vetor de coeficientes, $p_{t^{\prime}}$ e desvio padrão dos resíduos, $\sigma_{t^{\prime}}$. Assim, simula-se o efeito da mudança na distribuição da variável $e d$ do ano $t$ (1993 ou 2001) para o $t^{\prime}$ (2011), substituindo os valores da variável no ano $t$ (1993 ou 2001) pelos seguintes valores:

$$
e d_{i t^{\prime}} *=X_{i t} p_{t^{\prime}}+u_{i t} \frac{\sigma_{t^{\prime}}}{\sigma_{t}}
$$

Utilizando esta nova variável "educação" criada, reestima-se a participação no mercado de trabalho e a renda dos indivíduos (em função desta nova escolha ocupacional), para então calcular as medidas de pobreza e de desigualdade que serão comparadas com as observadas.

A reestimação da participação no mercado de trabalho foi realizada em duas etapas. Uma primeira etapa define se o indivíduo muda de status ocupacional. Na segunda etapa, definese a nova ocupação para aqueles indivíduos que mudaram de status. Na primeira etapa, precisamos de uma situação aleatória que nos indique se indivíduo muda de ocupação. Como a mudança é aleatória, sorteamos um número (condicional à probabilidade predita no logit multinomial a partir dos valores observados) e comparamos com a probabilidade predita a partir da simulação. Abaixo, seguem detalhes desta parte do método.

Realiza-se um sorteio, ou seja, escolhe-se aleatoriamente um valor entre zero e a probabilidade predita da escolha ocupacional observada do indivíduo (isso porque queremos uma mudança aleatória, mas que leve em consideração as características do indivíduo, ou seja, sua ocupação observada). Então, compara-se este valor sorteado com o valor predito para esta ocupação na reestimação do logit multinomial (com simulação): se o valor sorteado é menor que este novo valor predito, o indivíduo permanece na mesma ocupação; se maior, o indivíduo muda. Para os que mudam, temos uma segunda etapa: realiza-se um reescalonamento das três probabilidades restantes (ou seja, de todas as situações ocupacionais, exceto a que era observada antes da simulação). Sorteia-se um número entre zero e um e compara com os valores rescalonados, como no exemplo a seguir. 
Supomos um indivíduo trabalhando como formal e com uma probabilidade predita (a partir dos valores observados) de 0,4 de ser formal calculada a partir do logit multinomial. Para sabermos a nova situação ocupacional após a simulação, calculamos a nova probabilidade predita a partir da simulação e comparamos com um valor sorteado (entre 0 e 0,4 , neste exemplo). Supomos, neste exemplo que o valor sorteado foi 0,3 . Temos que se o novo valor predito de ser formal for 0,7 , o indivíduo permanece formal e se a nova probabilidade predita for 0,2 , o indivíduo muda de estado ocupacional. Se o indivíduo muda de estado ocupacional, precisamos saber qual é este novo estado.

Assim, em uma segunda etapa, reescalonamos as demais probabilidades preditas (neste exemplo, informal, autônomo/empregador e não ocupado) a partir do logit multinomial da simulação para que somem 1 (um). Por exemplo, se a probabilidade de ser formal era de 0,4, supomos que as probabilidades de ser informal, autônomo e não ocupado eram respectivamente: $0,2,0,3$ e 0,1. Reescalonando, temos, 0,33, 0,5 e 0,17. Sorteamos, por fim, um número entre zero e um. Se o valor sorteado for menor que 0,33 o indivíduo vai para mercado informal, se maior que $0,83(1-0,17=0,83)$ vira não ocupado e entre 0,33 e 0,83 se transforma em autônomo/empregador.

Dada a ocupação do indivíduo, agora analisaremos o rendimento. A partir dos parâmetros e das variáveis explicativas das equações 3, 4 e 5 (utilizando essa nova variável de educação) recuperamos a renda do indivíduo. É importante notar que imputamos o resíduo da equação de rendimento do indivíduo, já que sua ausência viesaria as estimações. A imputação desse resíduo ocorre da seguinte forma: se o indivíduo trabalhava (independentemente do setor), utiliza-se o resíduo já calculado originalmente para ele. Se o indivíduo não trabalhava, então não há um resíduo observado para ele. Assim, precisamos gerar um resíduo para cada um destes indivíduos: criamos uma variável que gera aleatoriamente um valor a partir de uma distribuição normal, com média zero e desvio-padrão cujo valor é o que foi encontrado na estimação correspondente (ou seja, são seis possibilidades: já que temos equações para formais, informais e autônomos/empregadores, diferenciando entre homens e mulheres). 
No caso da simulação utilizando os parâmetros (efeito preço), substituímos o parâmetro estimado de um ano $t$ em outro ano $t^{\prime}$. Por exemplo, se queremos simular o impacto do retorno da educação do ano de 2011 no ano de 1993, substituímos o parâmetro estimado para a educação em 2011 na equação de 1993. Suponha que estimamos os rendimentos para 1993 e 2011, respectivamente:

$$
\begin{aligned}
& \hat{Y}_{93}=\hat{a}_{93}+\hat{b}_{93} X_{93} \\
& \hat{Y}_{11}=\hat{a_{11}}+\hat{b}_{11} X_{11}
\end{aligned}
$$

Podemos, então, substituir o parâmetro estimado para 2011 na equação do ano de 1993: $\hat{Y}_{93}^{b 11}=\hat{a}_{93}+\hat{b}_{11} X_{93}$

Aqui também imputamos o resíduo da regressão da renda, assim como na simulação do efeito quantidade. Porém, nesta simulação, como os indivíduos não mudam de ocupação, não é necessário gerar um resíduo aleatoriamente, porque todos já possuem o resíduo observado (estimado anteriormente).

Temos assim, a distribuição de renda simulada para 1993 com o parâmetro referente ao retorno da educação de 2011. Podemos então, comparar a distribuição de renda simulada com a verdadeira distribuição de renda para o ano de 1993, calculada a partir dos dados observados. Desta forma, conseguiremos isolar o efeito do retorno da educação.

A partir das distribuições, observadas e simuladas, podemos calcular diversas medidas de pobreza e de desigualdade de renda e assim, comparar as mudanças nas distribuições de renda, isolando-se o efeito de cada variável (ou parâmetro). As medidas de desigualdade incluem o coeficiente de Gini e os índices de Entropia Generalizada: Theil-L ou E(0) e TheilT ou E(1), sendo que o primeiro é mais sensível a mudanças na cauda inferior da distribuição do que o segundq

$\overline{6}$ Nos índices de Entropia Generalizada, $\mathrm{E}(\alpha)$, o parâmetro $\alpha$ representa o peso dado às distâncias entre rendas de diferentes partes da distribuição, podendo tomar qualquer valor real. 
Também utilizamos a classe de medidas de pobreza de Foster, Greer \& Thorbecke: proporção de pobres (captura a incidência da pobreza), hiato de pobreza (média das diferenças das rendas dos pobres em relação à linha de pobreza) e quadrado do hiato de pobreza (maior peso para rendas dos pobres que estão mais longe da linha de pobreza).

As linhas de pobreza e de extrema pobreza adotadas são atualizações dos cálculos de Sônia Rocha e seus valores são apresentados em anexo (Anexo A). A metodologia para construção dessas linhas de pobreza se encontra em [Rocha 2003] e um resumo, no anexo B. 


\section{DADOS}

A base de dados utilizada neste trabalho é a Pnad (Pesquisa Nacional por Amostra de Domicílios) disponibilizada pelo IBGE (Instituto Brasileiro de Geografia e Estatística) e os dados foram coletados para os anos de 1993, 2001 e 2011.

A seguir, algumas considerações: a Pnad passa a abranger a área rural da região Norte do país a partir de 2004. Por este motivo, retiramos as observações referentes à região Norte rural em 2011, para que os dados de cada ano sejam comparáveis. Outra questão é a de que as perguntas a respeito de rendimento e trabalho são respondidas por todos aqueles com 10 anos de idade ou mais, por esta razão utilizamos esse recorte da amostra para calcular as estimações e simulações, ainda que as observações para menores de 10 anos sejam utilizadas na construção de algumas variáveis do modelo.

A partir da tabela 1, podemos verificar o número de observações da amostra para todos os anos sem nenhum recorte e também para o recorte aqui considerado: indivíduos com 10 anos de idade ou mais.

A seguir, realizamos uma análise descritiva (para a amostra de dados) das principais variáveis que utilizaremos neste estudo. Na tabela 2, podemos acompanhar a variação na quantidade de moradores por domicílio entre os anos estudados. Fica clara uma tendência de aumento na proporção de domicílios com poucos moradores (até 3 indivíduos) ao longo do tempo. Para os domicílios mais numerosos (a partir de 5 moradores), a tendência é oposta. Enquanto que em 1993, 12,24\% dos domicílios possuíam 6 moradores, em 2011, essa categoria representa apenas $6,78 \%$ do total dos domicílios. 
Tabela 1 - Número de observações na amostra

\begin{tabular}{l||c|c|c}
\hline Amostra/Ano & 1993 & 2001 & 2011 \\
\hline \hline Apenas para maiores de 10 anos & 244.650 & 299.434 & 290.403 \\
\hline Total & 322.205 & 378.837 & 346.617 \\
\hline
\end{tabular}

Fonte: Cálculos do autor baseados na Pnad

Este aspecto, no qual os domicílios passam a apresentar um menor número de moradores, pode estar atrelado à redução do número de filhos por casal que vem ocorrendo no Brasil desde a década de 70, mas que se acentuou recentemente. A questão da composição do domicílio é muito importante no estudo da pobreza, uma vez que afeta diretamente a quantidade de pessoas no mercado de trabalho, que estão, portanto, gerando renda. Leone, Maia e Baltar 2010

Já na tabela 3, vemos a distribuição dos domicílios segundo sua localização, ou seja, se este se encontra em uma região urbana ou rural. Ao longo dos anos, houve um aumento na porcentagem de domicílios presentes na região urbana em detrimento dos situados nas áreas rurais. Esta questão é relevante em nosso estudo, principalmente, porque a formação da renda de um indivíduo pode variar ao considerarmos a região na qual o indivíduo exerce sua atividade. Como vimos na revisão bibliográfica, existem inclusive estudos relatando maior grau de desigualdade em regiões urbanas do que em rurais, por se tratarem de áreas mais heterogêneas.

A partir da tabela 4, analisamos a porcentagem dos moradores dos domicílios que são chefes de família. Como podemos verificar, em 1993, 32,77\% dos moradores eram chefes de família, enquanto que em 2001, este número é 34,56\% e em 2011 eleva-se para 37,45\%. Este cenário é justificado por um aumento no número de indivíduos morando sozinhos. 
Tabela 2 - Número de moradores por domicílio (porcentagem)

\begin{tabular}{c||c|c|c}
\hline Quantidade de moradores/Ano & 1993 & 2001 & 2011 \\
\hline \hline 1 & 2,51 & 3,33 & 4,77 \\
\hline 2 & 9,75 & 11,80 & 17,20 \\
\hline 3 & 15,99 & 19,34 & 24,58 \\
\hline 4 & 21,85 & 24,86 & 25,48 \\
\hline 5 & 17,94 & 17,76 & 14,35 \\
\hline 6 & 12,24 & 9,94 & 6,78 \\
\hline 7 & 7,42 & 5,38 & 3,41 \\
\hline 8 ou mais & 12,30 & 7,59 & 3,43 \\
\hline Total & 100 & 100 & 100 \\
\hline № observações & 244.650 & 299.434 & 290.403 \\
\hline
\end{tabular}

Fonte: Cálculos do autor baseados na Pnad

Tabela 3 - Localização do domicílio (porcentagem)

\begin{tabular}{l||c|c|c}
\hline Condição/Ano & 1993 & 2001 & 2011 \\
\hline \hline Urbano & 81,99 & 86,10 & 88,72 \\
\hline Rural & 18,01 & 13,90 & 11,28 \\
\hline Total & 100 & 100 & 100 \\
\hline № observações & 244.650 & 299.434 & 290.403 \\
\hline
\end{tabular}

Fonte: Cálculos do autor baseados na Pnad 
Tabela 4 - Características do domicílio (porcentagem)

\begin{tabular}{l||c|c|c}
\hline Posição/Ano & 1993 & 2001 & 2011 \\
\hline \hline Chefe & 32,77 & 34,56 & 37,45 \\
\hline Cônjuge & 24,07 & 23,85 & 24,38 \\
\hline Filho & 34,48 & 32,87 & 29,19 \\
\hline Outro parente & 7,26 & 7,68 & 8,10 \\
\hline Demais & 1,42 & 1,04 & 0,88 \\
\hline Total & 100 & 100 & 100 \\
\hline № observações & 244.650 & 299.434 & 290.403 \\
\hline \hline Domicílios com pai e mãe presentes & 73,45 & 69,01 & 65,10 \\
\hline
\end{tabular}

Fonte: Cálculos do autor baseados na Pnad

Outra informação importante reportada na tabela 4 é a porcentagem de domicílios com pai e mãe presentes. Observa-se que este valor vem diminuindo, possivelmente relacionado ao maior número de divórcios que vem ocorrendo no país ao longo dos últimos anos.

Observando a tabela 5 , podemos inferir alguns resultados a respeito da idade da população brasileira no período abordado (vale lembrar que como não estamos lidando com dados para pessoas com menos de 10 anos de idade, estes valores não são reportados em nossa análise descritiva dos dados). A estrutura populacional do Brasil vem se modificando ao longo dos últimos anos, de forma que a pirâmide etária passou a ter uma base mais estreita (menor porcentagem de jovens), enquanto que o topo se alargou (crescimento no número de idosos). Esta realidade pode ser visualizada observando que a população entre 10 e 20 anos de idade passou de 28,55\% da população para 25,81\% em 2001 e para 21,05\%, em 2011. Já a população mais idosa vem aumentado, passando de 9,22\% da população (com 10 anos de idade ou mais) em 1993 para 12,83\% em 2011. 
Tabela 5 - Faixa etária da população (porcentagem)

\begin{tabular}{l||c|c|c}
\hline Idade/Ano & 1993 & 2001 & 2011 \\
\hline \hline Entre 10 e 20 anos & 28,55 & 25,81 & 21,05 \\
\hline Entre 21 e 30 anos & 22,49 & 21,86 & 20,22 \\
\hline Entre 31 e 40 anos & 18,50 & 18,72 & 18,23 \\
\hline Entre 41 e 60 anos & 21,16 & 23,47 & 27,67 \\
\hline Mais de 60 anos & 9,22 & 10,14 & 12,83 \\
\hline Total & 100 & 100 & 100 \\
\hline № observações & 244.620 & 299.396 & 290.403 \\
\hline
\end{tabular}

Fonte: Cálculos do autor baseados na Pnad

Tabela 6 - Gênero da população (porcentagem)

\begin{tabular}{l||c|c|c}
\hline Gênero/Ano & 1993 & 2001 & 2011 \\
\hline \hline População & 51,69 & 51,95 & 52,22 \\
\hline Feminino & 48,31 & 48,05 & 47,78 \\
\hline Masculino & 100 & 100 & 100 \\
\hline Total & 244.650 & 299.434 & 290.403 \\
\hline No observações
\end{tabular}

Chefe de família

\begin{tabular}{l||c|c|c}
\hline Feminino & 20,57 & 25,41 & 37,71 \\
\hline Masculino & 79,43 & 74,59 & 62,69 \\
\hline Total & 100 & 100 & 100 \\
\hline № observações & 80.167 & 103.483 & 108.731 \\
\hline
\end{tabular}

Fonte: Cálculos do autor baseados na Pnad 
Tabela 7 - Nível de escolaridade da população (porcentagem)

\begin{tabular}{l||c|c|c}
\hline Grupo de estudo/Ano & 1993 & 2001 & 2011 \\
\hline \hline Sem instrução e menos de 1 ano & 16,23 & 12,69 & 11,25 \\
\hline 1 a 3 anos & 10,94 & 7,74 & 4,47 \\
\hline 4 a 7 anos & 40,12 & 35,19 & 24,87 \\
\hline 8 a 10 anos & 14,68 & 18,28 & 19,04 \\
\hline 11 a 14 anos & 13,32 & 20,37 & 30,30 \\
\hline 15 anos ou mais & 4,72 & 5,74 & 10,08 \\
\hline Total & 100 & 100 & 100 \\
\hline № observações & 243.875 & 297.026 & 289.711 \\
\hline
\end{tabular}

Fonte: Cálculos do autor baseados na Pnad

Quanto ao gênero, vemos na tabela 6, que a população brasileira vem apresentando uma maioria de mulheres em todos os anos. Na mesma tabela, podemos observar o gênero dos chefes de família ao longo do tempo. Enquanto que em 1993, apenas $20 \%$ dos chefes de família eram mulheres, em 2011 este valor pula para cerca de 37\%.

A partir da tabela 7, vemos a variação do nível de escolaridade da população, variável de maior interesse deste estudo. Podemos perceber que, há um aumento da porcentagem da população com 10 anos ou mais que apresenta maiores níveis de escolaridade em detrimento dos níveis mais baixos. Entretanto, a porcentagem da população sem instrução ou com menos de um ano de estudo ainda é relativamente muito alta (11\%).

Com relação à variável que utilizamos como instrumento na estimação dos rendimentos no caso das mulheres (renda do domicílio deduzida da renda da mulher), podemos observar a tabela 8. Tal renda apresenta pequeno aumento ao longo do tempd7.

7 É importante observar que os valores das tabelas 8, 11 e 12 estão expressos em Reais (R\$). Isso exigiu a conversão dos valores monetários de 1993 (Cruzeiro Real). Além disso, os valores foram deflacionados, sendo expressos em valores de 2012. Os deflatores utilizados foram os disponibilizados pelo Ipea. 
Tabela 8 - Renda do domicílio líquida da renda da mulher (média mensal em $\mathrm{R} \$$ de 2012)

\begin{tabular}{l||c|c|c}
\hline Renda/Ano & 1993 & 2001 & 2011 \\
\hline \hline Renda média & $1.966,77$ & $2.027,93$ & $2.252,74$ \\
\hline № observações & 122.130 & 152.086 & 143.064 \\
\hline
\end{tabular}

Fonte: Cálculos do autor baseados na Pnad

Uma questão que já abordamos é a existência de um viés de seleção com relação à decisão de participação no mercado de trabalho para as mulheres. Na tabela 9, observa-se que há uma clara predominância dos homens no mercado de trabalho, sendo que estes representam cerca de 60\% da População Economicamente Ativa (PEA) em 1993. Há uma redução deste número para os homens ao longo do tempo, mas mesmo em 2011, os homens representam ainda 56\% da PEA. Ainda na tabela 9, vemos que entre as mulheres apenas metade faz parte da PEA em qualquer um dos anos, enquanto que para os homens, mais de $70 \%$ são economicamente ativos.

Com relação aos setores ocupacionais escolhidos, vemos na tabela 10 que houve um aumento na porcentagem da população com empregos formais, passando de cerca de $38 \%$ em 1993 e 2001 para 49\% em 2011. Também na tabela 10, podemos observar a condição do trabalho por gênero. Tanto para as mulheres quanto para os homens, a maioria está empregada no setor formal. É interessante notar que a segunda opção de trabalho mais frequente para as mulheres é o setor informal, enquanto que para os homens é o trabalho como autônomo/empregador.

Quanto aos rendimentos apresentados durante o período, vemos na tabela 11 que houve um aumento da renda domiciliar média ao longo dos anos, assim como da renda per-capita. Vale ressaltar que, o crescimento da renda por si só não garante melhores índices de pobreza e de desigualdade, já que depende de como este incremento de renda é distribuído pela população. Ainda na mesma tabela, vemos a renda média proveniente do trabalho por setor 
Tabela 9 - População Economicamente Ativa (porcentagem)

\begin{tabular}{r|r|r}
\cline { 2 - 3 } 1993 & 2001 & 2011 \\
\hline
\end{tabular}

Distribuição dos ativos por gênero

\begin{tabular}{l||c|c|c}
\hline Homem & 60,01 & 57,83 & 56,37 \\
\hline Mulher & 39,99 & 42,17 & 43,63 \\
\hline Total & 100 & 100 & 100 \\
\hline № observações & 152.033 & 184.387 & 176.834 \\
\hline
\end{tabular}

Distribuição das mulheres, por situação

\begin{tabular}{l||c|c|c}
\hline PEA & 48,08 & 49,98 & 50,87 \\
\hline Não PEA & 51,92 & 50,02 & 49,13 \\
\hline Total & 100 & 100 & 100 \\
\hline № observações & 126.452 & 155.556 & 151.660 \\
\hline
\end{tabular}

Distribuição dos homens, por situação

\begin{tabular}{l||c|c|c}
\hline PEA & 77,19 & 74,11 & 71,85 \\
\hline Não PEA & 22,81 & 25,89 & 28,15 \\
\hline Total & 100 & 100 & 100 \\
\hline № observações & 118.198 & 143.878 & 138.743 \\
\hline
\end{tabular}

Fonte: Cálculos do autor baseados na Pnad 
Tabela 10 - Condição do emprego (porcentagem)

\begin{tabular}{|c|c|c|c|}
\hline Condição de trabalho/Ano & 1993 & 2001 & 2011 \\
\hline \multicolumn{4}{|l|}{ População } \\
\hline Formal* & 37,51 & 37,76 & 48,80 \\
\hline Informal** & 23,35 & 24,99 & 20,47 \\
\hline Autônomo/empregador $* * *$ & 25,22 & 26,74 & 24,44 \\
\hline Demais $* * * *$ & 13,86 & 10,29 & 6,18 \\
\hline Sem declaração & 0,06 & 0,22 & 0,11 \\
\hline № observações & 141.714 & 166.488 & 164.249 \\
\hline \multicolumn{4}{|l|}{ Mulher } \\
\hline Formal* & 35,82 & 38,11 & 49,38 \\
\hline Informal ${ }^{* *}$ & 25,16 & 27,52 & 23,91 \\
\hline Autônomo/empregador ${ }^{* * *}$ & 17,79 & 19,29 & 18,30 \\
\hline Demais $* * * *$ & 21,17 & 14,99 & 8,38 \\
\hline Sem declaração & 0,06 & 0,09 & 0,03 \\
\hline № observações & 55.795 & 68.138 & 69.737 \\
\hline \multicolumn{4}{|l|}{ Homem } \\
\hline Formal* & 38,62 & 37,53 & 48,40 \\
\hline Informal** & 22,18 & 23,24 & 17,92 \\
\hline Autônomo/empregador $* * *$ & 30,04 & 31,90 & 28,96 \\
\hline Demais $* * * *$ & 9,12 & 7,02 & 4,56 \\
\hline Sem declaração & 0,04 & 0,31 & 0,16 \\
\hline № observações & 85.919 & 98.356 & 94.512 \\
\hline \multicolumn{4}{|c|}{ * Empregado com carteira, militar e funcionário público estatutário. } \\
\hline \multicolumn{4}{|l|}{ ** Empregado sem carteira. } \\
\hline \multicolumn{4}{|l|}{ *** Conta-própria e empregador. } \\
\hline 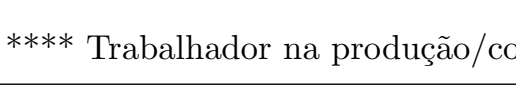 & & & \\
\hline
\end{tabular}


Tabela 11 - Renda (média mensal em R $\$$ de 2012)

\begin{tabular}{l||c|c|c}
\hline Renda/Ano & 1993 & 2001 & 2011 \\
\hline \hline Por domicílio & $2.217,96$ & $2.377,95$ & $2.795,40$ \\
\hline Per-capita & 451,45 & 536,57 & 727,61 \\
\hline № observações & 236.319 & 292.672 & 273.939 \\
\hline Do trabalho & & & \\
\hline Formal & $1.318,63$ & $1.390,07$ & $1.560,12$ \\
\hline Informal & 439,32 & 626,17 & 804,86 \\
\hline Autônomo/empregador & $1.357,67$ & $1.436,05$ & $1.694,64$ \\
\hline
\end{tabular}

Fonte: Cálculos do autor baseados na Pnad

ocupacional. Observamos que em todos os anos o setor que possui menor renda na média é o informal, enquanto que o autônomo/empregador ganha mais, na média.

Sobre a questão de recebimentos de renda não provenientes do trabalho, um ponto interessante é que o valor real médio investido na poupança caiu, mas a porcentagem de indivíduos que possuem poupança elevou-se ao longo dos anos estudados, como vemos na tabela 12.

Por fim, na tabela 13, observamos o valor calculado para cada indicador de pobreza e de desigualdade de renda considerado, utilizando os dados observados. Nota-se uma redução da pobreza ao longo do tempo independente do indicador avaliado. O mesmo pode ser observado para os indicadores de pobreza que utilizam linhas de extrema pobreza. Com relação à desigualdade de renda, esta também se reduz, passando de um índice de Gini de 0,607 em 1993 para 0,540 em 2011 $\unlhd^{8}$. São estes valores da tabela 13 que utilizaremos para realizar comparações com os indicadores calculados a partir das novas distribuições que surgirem com as simulações (quarta etapa da metodologia).

8 As linhas de pobreza e de extrema pobreza utilizadas neste cálculo estão na tabela A.3 em anexo. 


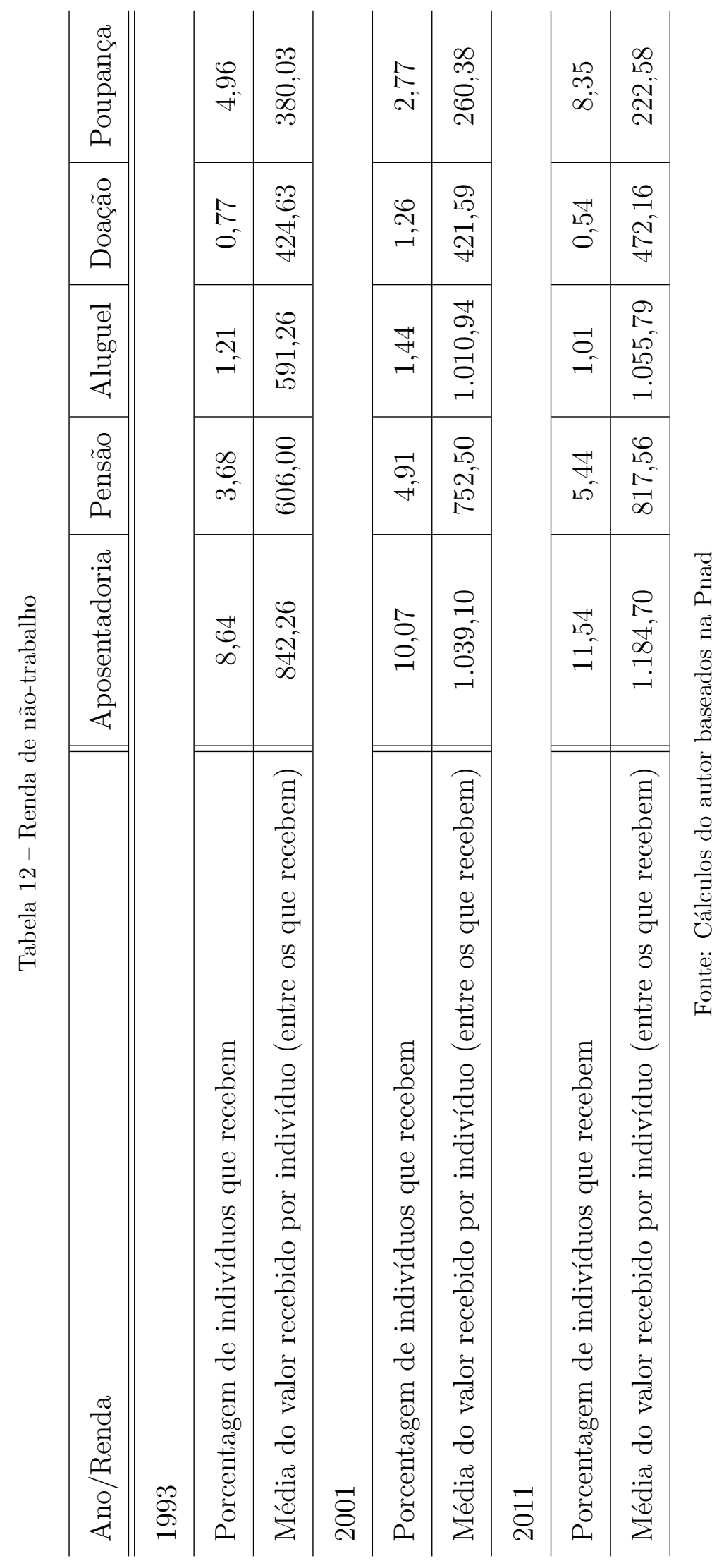


Tabela 13 - Indicadores de pobreza e de desigualdade de renda

\begin{tabular}{|c|c|c|c|}
\hline Indicadores / Ano & 1993 & 2001 & 2011 \\
\hline \multicolumn{4}{|l|}{ Pobreza } \\
\hline Proporção de Pobres - P(0) & 42,766 & 34,612 & 18,403 \\
\hline Hiato de Pobreza - P(1) & 20,634 & 15,870 & 8,579 \\
\hline Quadrado do hiato de pobreza - $\mathrm{P}(2)$ & 13,148 & 9,957 & 5,94 \\
\hline \multicolumn{4}{|l|}{ Extrema pobreza } \\
\hline Proporção de Pobres - P(0) & 13,955 & 9,717 & 5,84 \\
\hline Hiato de Pobreza - P(1) & 6,355 & 4,799 & 3,974 \\
\hline Quadrado do hiato de pobreza - $\mathrm{P}(2)$ & 4,264 & 3,519 & 3,367 \\
\hline \multicolumn{4}{|l|}{ Desigualdade de renda } \\
\hline Índice de Gini & 0,607 & 0,596 & 0,540 \\
\hline Índice de Theil-L (E(0)) & 0,666 & 0,616 & 0,472 \\
\hline Índice de Theil-T (E(1)) & 0,779 & 0,724 & 0,590 \\
\hline
\end{tabular}

Fonte: Cálculos do autor baseados na Pnad 


\section{RESULTADOS}

Nesta seção, apresentamos os resultados deste estudo, que estão divididos em dois tipos. O primeiro tipo se refere à estimação do modelo (equações de rendimento e de participação no mercado de trabalho). Estes resultados mostram a real situação dos dados, ou seja, não há nenhuma simulação ainda. Posteriormente, apresentamos os resultados relacionados às simulações realizadas. São os resultados encontrados a partir da quarta e última etapa da metodologia descrita anteriormente.

\subsection{Resultados das estimações}

Iniciamos a análise com as equações de rendimento. Na estimação para as mulheres, como já explicado na metodologia deste trabalho, utilizamos o procedimento de Heckman. Assim, no primeiro estágio, estimamos uma equação de seleção para todas as mulheres utilizando como instrumento a renda do domicílio deduzida da renda da mulher, sob a suposição de que há uma seleção. Note que a ideia é que a seleção está na decisão por trabalhar e não, na decisão em qual setor de atividade econômica a mulher opta por trabalhar. Por esta razão, esta primeira etapa foi calculada para todas as mulheres, sem dividir em setores ocupacionais.

Os resultados desta primeira etapa estão na tabela A.1 no apêndice A. Analisando-se a parte B desta tabela, vemos que todas as variáveis são significativos a 1\%. Também podemos observar que os valores estimados para o instrumento (a renda do domicílio líquida da renda da mulher) em todos os anos, são significativos a 1\% e negativos, o que era esperado: quanto maior a renda do domicílio (sem considerar a própria renda da mulher) menor a probabilidade de ela trabalhar, em qualquer atividade. 
A partir da equação de seleção anteriormente estimada, obtemos a razão inversa de Mills para cada mulher, a ser utilizada no segundo estágio da estimação, diferenciando-se para cada atividade econômica. Os resultados referentes a esta segunda etapa (equação principal) podem ser vistos nas próximas tabelas (já que esta etapa é realizada para cada setor ocupacional, separadamente).

Nas tabelas 14, 15 e 16, apresentamos os resultados da estimação das equações de rendimento (para formais, informais e autônomos/empregadores). Como podemos observar, para os homens, os coeficientes estimados são todos significativos a $1 \%$ em qualquer uma das atividades econômicas (exceto educação ao quadrado para informais em 1993). Também nota-se que os sinais são majoritariamente os esperados: educação, educação ao quadrado e experiência positivos e experiência ao quadrado negativa (exceto educação para formais em 2001 e 2011). O coeficiente relacionado a região urbana também é positivo, o que é esperado: salários maiores para trabalhadores de regiões urbanas.

Com relação à magnitude dos coeficientes para os homens, observa-se uma redução do impacto positivo da educação sobre a formação da renda de todos os trabalhadores (essa queda deve ser destacada, uma vez que os parâmetros para educação serão substituídos na simulação efeito preço, como vimos na descrição da metodologia). Assim como a experiência que vem diminuindo seu impacto positivo ao longo dos anos, em todas as tabelas. Também é interessante notar que a experiência teve impactos diferentes entre os grupos principalmente em 2011, tendo um maior destaque para trabalhadores informais $(0,074)$ e autônomos/empregadores $(0,079)$ do que para formais $(0,049)$. Outro ponto importante é que os coeficientes referentes à região urbana são maiores para autônomos do que para os demais.

Agora analisaremos as estimações realizadas para as mulheres - é importante ressaltar que nas tabelas 14, 15 e 16 estão apresentados os resultados do segundo estágio da estimação por Heckman, já que o primeiro estágio foi retratado na tabela A.1 do apêndice A. Constatamos que quase todos os coeficientes também se mostram significativos a pelo menos $10 \%$. 
Os sinais também são os esperados para quase todos os anos e em todos os grupos de trabalhadoras, assim como no caso dos homens, com exceção apenas do coeficiente da educação nos anos de 2001 e de 2011, para trabalhadoras formais.

Em todas as tabelas, obervamos que para as mulheres, houve uma redução do efeito da educação sobre a formação do salário entre 1993 e 2011. Sobre a experiência, seu efeito marginal parece ter aumentado, principalmente de 1993 para 2011, para as trabalhadoras formais e reduzido para as informais e autônomas.

Com relação à razão inversa de Mills, podemos perceber que esta é significativo a pelo menos $5 \%$ em todos os anos e ocupações, o que reforça o indício de existência de um viés de seleção no caso da escolha da mulher por trabalhar (vale ressaltar, que a estimação não garante que tal viés tenha sido corrigido). Além disso, a razão de Mills apresenta o sinal positivo, que era esperado: as variáveis que explicam a seleção estão positivamente correlacionadas com a renda.

Por fim, para podermos visualizar melhor o quanto varia o efeito marginal da educação sobre a formação dos rendimentos ao longo dos anos considerados, temos as figuras 1 e 2 . Como podemos verificar, o impacto da educação difere entre homens e mulheres, sendo que para elas o efeito é sempre maior (independentemente do setor ocupacional considerado).

Considerando os homens, em todos os setores, o efeito da educação diminuiu ao longo do tempo apenas para os menos escolarizados, enquanto que para os mais escolarizados o efeito marginal é maior em 2011 do que em 1993. Já para as mulheres o efeito marginal da educação é sempre menor em 2011 do que nos outros anos, exceto para as mais escolarizadas no setor formal (cujo efeito marginal em 2011 passa a ser maior do que em 1993, a partir de 12 anos de estudo) 
Tabela 14 - Equação de rendimentos: Regressão* para Trabalhadores Formais

\begin{tabular}{|c|c|c|c|c|c|c|}
\hline Variável/Ano & \multicolumn{2}{|c|}{1993} & \multicolumn{2}{|c|}{2001} & \multicolumn{2}{|c|}{2011} \\
\hline \multicolumn{7}{|c|}{ Homem } \\
\hline & Coeficiente & p-valor & Coeficiente & p-valor & Coeficiente & $\mathrm{p}$-valor \\
\hline Educação & 0,031 & 0,000 & $-0,010$ & 0,002 & $-0,060$ & 0,000 \\
\hline Educação ${ }^{2}$ & 0,005 & 0,000 & 0,008 & 0,000 & 0,009 & 0,000 \\
\hline Experiência & 0,094 & 0,000 & 0,085 & 0,000 & 0,049 & 0,000 \\
\hline Experiência $^{2}$ & $-0,001$ & 0,000 & $-0,001$ & 0,000 & 0,000 & 0,000 \\
\hline Urbano & 0,202 & 0,000 & 0,190 & 0,000 & 0,089 & 0,000 \\
\hline Intercepto & 4,177 & 0,000 & 4,404 & 0,000 & 5,483 & 0,000 \\
\hline $\mathrm{R}^{2}$ & \multicolumn{2}{|c|}{0,434} & \multicolumn{2}{|c|}{0,480} & \multicolumn{2}{|c|}{0,399} \\
\hline № observações & \multicolumn{2}{|c|}{32.761} & \multicolumn{2}{|c|}{36.072} & \multicolumn{2}{|c|}{43.997} \\
\hline \multicolumn{7}{|c|}{ Mulher } \\
\hline & Coeficiente & p-valor & Coeficiente & p-valor & Coeficiente & p-valor \\
\hline Educação & 0,008 & 0,318 & $-0,024$ & 0,001 & $-0,057$ & 0,000 \\
\hline Educação² & 0,009 & 0,000 & 0,012 & 0,000 & 0,012 & 0,000 \\
\hline Experiência & 0,131 & 0,002 & 0,163 & 0,000 & 0,146 & 0,000 \\
\hline Experiência $^{2}$ & $-0,002$ & 0,004 & $-0,002$ & 0,000 & $-0,002$ & 0,000 \\
\hline Urbano & 0,691 & 0,000 & 0,494 & 0,000 & 0,433 & 0,000 \\
\hline Mills & 1,111 & 0,028 & 1,244 & 0,000 & 1,158 & 0,000 \\
\hline Intercepto & 1,635 & 0,238 & 1,182 & 0,104 & 2,008 & 0,001 \\
\hline $\mathrm{R}^{2}$ & \multicolumn{2}{|c|}{0,387} & \multicolumn{2}{|c|}{0,485} & \multicolumn{2}{|c|}{0,431} \\
\hline № observações & \multicolumn{2}{|c|}{19.293} & \multicolumn{2}{|c|}{25.067} & \multicolumn{2}{|c|}{32.160} \\
\hline
\end{tabular}

*Regressões ponderadas para a população.

Fonte: Cálculos do autor baseados na Pnad 
Tabela 15 - Equação de rendimentos: Regressão* para Trabalhadores Informais

\begin{tabular}{|c|c|c|c|c|c|c|}
\hline Variável/Ano & \multicolumn{2}{|c|}{1993} & \multicolumn{2}{|c|}{2001} & \multicolumn{2}{|c|}{2011} \\
\hline \multicolumn{7}{|c|}{ Homem } \\
\hline & Coeficiente & p-valor & Coeficiente & p-valor & Coeficiente & $\mathrm{p}$-valor \\
\hline Educação & 0,104 & 0,000 & 0,051 & 0,000 & 0,014 & 0,003 \\
\hline Educação ${ }^{2}$ & 0,001 & 0,182 & 0,004 & 0,000 & 0,005 & 0,000 \\
\hline Experiência & 0,094 & 0,000 & 0,099 & 0,000 & 0,074 & 0,000 \\
\hline Experiência $^{2}$ & $-0,001$ & 0,000 & $-0,001$ & 0,000 & $-0,001$ & 0,000 \\
\hline Urbano & 0,295 & 0,000 & 0,259 & 0,000 & 0,287 & 0,000 \\
\hline Intercepto & 3,376 & 0,000 & 3,550 & 0,000 & 4,286 & 0,000 \\
\hline $\mathrm{R}^{2}$ & \multicolumn{2}{|c|}{0,357} & \multicolumn{2}{|c|}{0,401} & \multicolumn{2}{|c|}{0,340} \\
\hline № observações & \multicolumn{2}{|c|}{18.814} & \multicolumn{2}{|c|}{22.412} & \multicolumn{2}{|c|}{16.318} \\
\hline \multicolumn{7}{|c|}{ Mulher } \\
\hline & Coeficiente & p-valor & Coeficiente & p-valor & Coeficiente & p-valor \\
\hline Educação & 0,087 & 0,000 & 0,046 & 0,000 & 0,016 & 0,017 \\
\hline Educação $^{2}$ & 0,008 & 0,000 & 0,010 & 0,000 & 0,010 & 0,000 \\
\hline Experiência & 0,259 & 0,000 & 0,238 & 0,000 & 0,230 & 0,000 \\
\hline Experiência $^{2}$ & $-0,003$ & 0,000 & $-0,003$ & 0,000 & $-0,003$ & 0,000 \\
\hline Urbano & 0,841 & 0,000 & 0,640 & 0,000 & 0,712 & 0,000 \\
\hline Mills & 2,063 & 0,000 & 1,632 & 0,000 & 1,614 & 0,000 \\
\hline Intercepto & $-2,699$ & 0,014 & $-1,504$ & 0,006 & $-1,147$ & 0,038 \\
\hline $\mathrm{R}^{2}$ & \multicolumn{2}{|c|}{0,298} & \multicolumn{2}{|c|}{0,374} & \multicolumn{2}{|c|}{0,285} \\
\hline № observações & \multicolumn{2}{|c|}{13.326} & \multicolumn{2}{|c|}{18.085} & \multicolumn{2}{|c|}{15.649} \\
\hline
\end{tabular}

*Regressões ponderadas para a população.

Fonte: Cálculos do autor baseados na Pnad 
Tabela 16 - Equação de rendimentos: Regressão* para Autônomos/Empregadores

\begin{tabular}{|c|c|c|c|c|c|c|}
\hline Variável/Ano & \multicolumn{2}{|c|}{1993} & \multicolumn{2}{|c|}{2001} & \multicolumn{2}{|c|}{2011} \\
\hline \multicolumn{7}{|c|}{ Homem } \\
\hline & Coeficiente & $\mathrm{p}$-valor & Coeficiente & $\mathrm{p}$-valor & Coeficiente & p-valor \\
\hline Educação & 0,177 & 0,000 & 0,135 & 0,000 & 0,071 & 0,000 \\
\hline Educação ${ }^{2}$ & $-0,003$ & 0,000 & 0,001 & 0,008 & 0,003 & 0,000 \\
\hline Experiência & 0,105 & 0,000 & 0,094 & 0,000 & 0,079 & 0,000 \\
\hline Experiência $^{2}$ & $-0,001$ & 0,000 & $-0,001$ & 0,000 & $-0,001$ & 0,000 \\
\hline Urbano & 0,283 & 0,000 & 0,401 & 0,000 & 0,501 & 0,000 \\
\hline Intercepto & 3,266 & 0,000 & 3,366 & 0,000 & 3,914 & 0,000 \\
\hline $\mathrm{R}^{2}$ & \multicolumn{2}{|c|}{0,353} & \multicolumn{2}{|c|}{0,405} & \multicolumn{2}{|c|}{0,339} \\
\hline № observações & \multicolumn{2}{|c|}{24.813} & \multicolumn{2}{|c|}{30.234} & \multicolumn{2}{|c|}{25.810} \\
\hline \multicolumn{7}{|c|}{ Mulher } \\
\hline & Coeficiente & p-valor & Coeficiente & $\mathrm{p}$-valor & Coeficiente & $\mathrm{p}$-valor \\
\hline Educação & 0,144 & 0,000 & 0,142 & 0,000 & 0,099 & 0,000 \\
\hline Educação $^{2}$ & 0,014 & 0,000 & 0,011 & 0,000 & 0,011 & 0,000 \\
\hline Experiência & 0,509 & 0,000 & 0,432 & 0,000 & 0,401 & 0,000 \\
\hline Experiência $^{2}$ & $-0,006$ & 0,000 & $-0,005$ & 0,000 & $-0,005$ & 0,000 \\
\hline Urbano & 1,493 & 0,000 & 1,123 & 0,000 & 1,346 & 0,000 \\
\hline Mills & 4,496 & 0,000 & 3,204 & 0,000 & 2,794 & 0,000 \\
\hline Intercepto & $-1,054$ & 0,001 & $-7,659$ & 0,000 & $-6,448$ & 0,000 \\
\hline $\mathrm{R}^{2}$ & \multicolumn{2}{|c|}{0,377} & \multicolumn{2}{|c|}{0,438} & \multicolumn{2}{|c|}{0,342} \\
\hline № observações & \multicolumn{2}{|c|}{9.317} & \multicolumn{2}{|c|}{12.446} & \multicolumn{2}{|c|}{11.739} \\
\hline
\end{tabular}

*Regressões ponderadas para a população. 
Figura 1 - Efeito marginal da educação na formação da renda (homens)
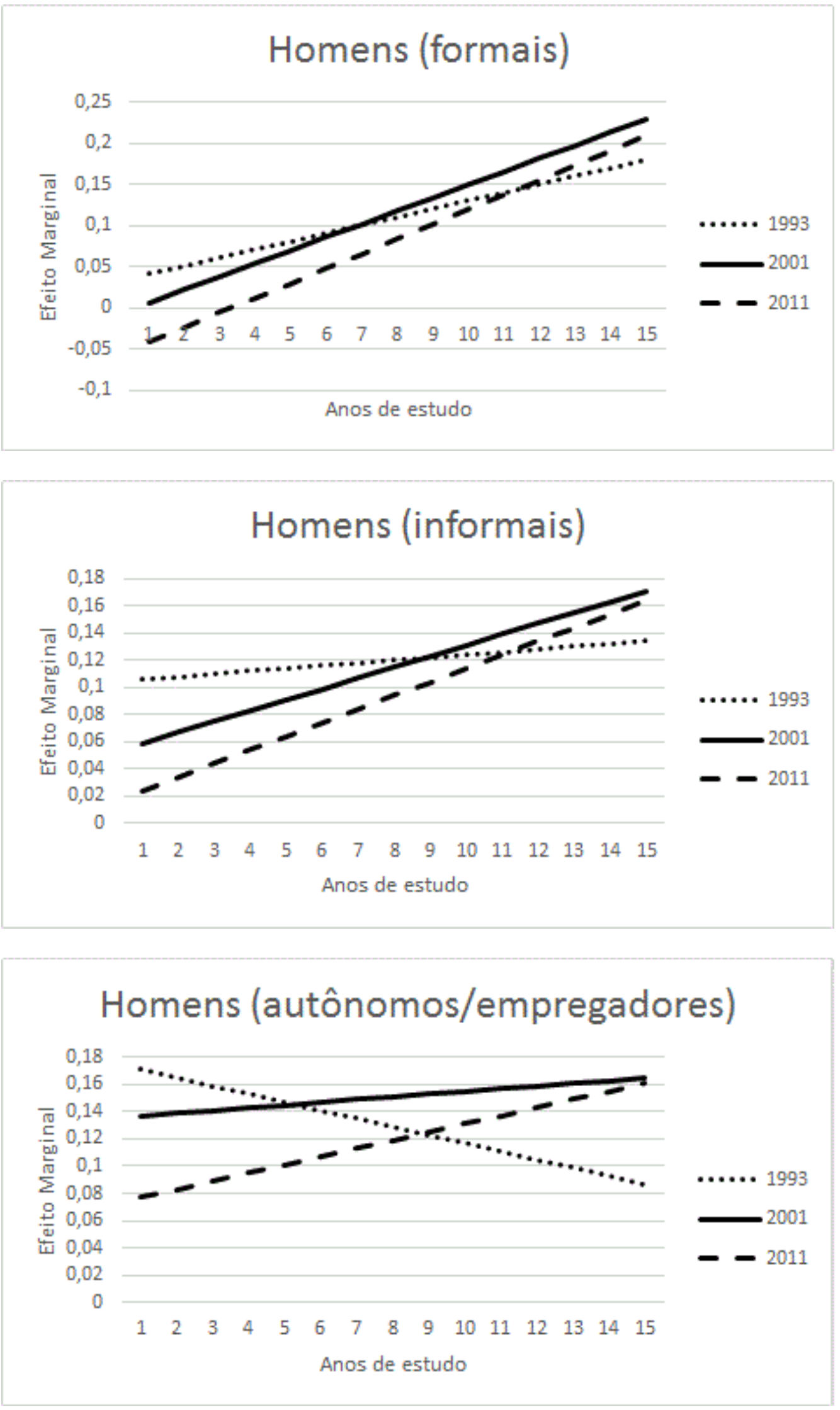
Figura 2 - Efeito marginal da educação na formação da renda (mulheres)
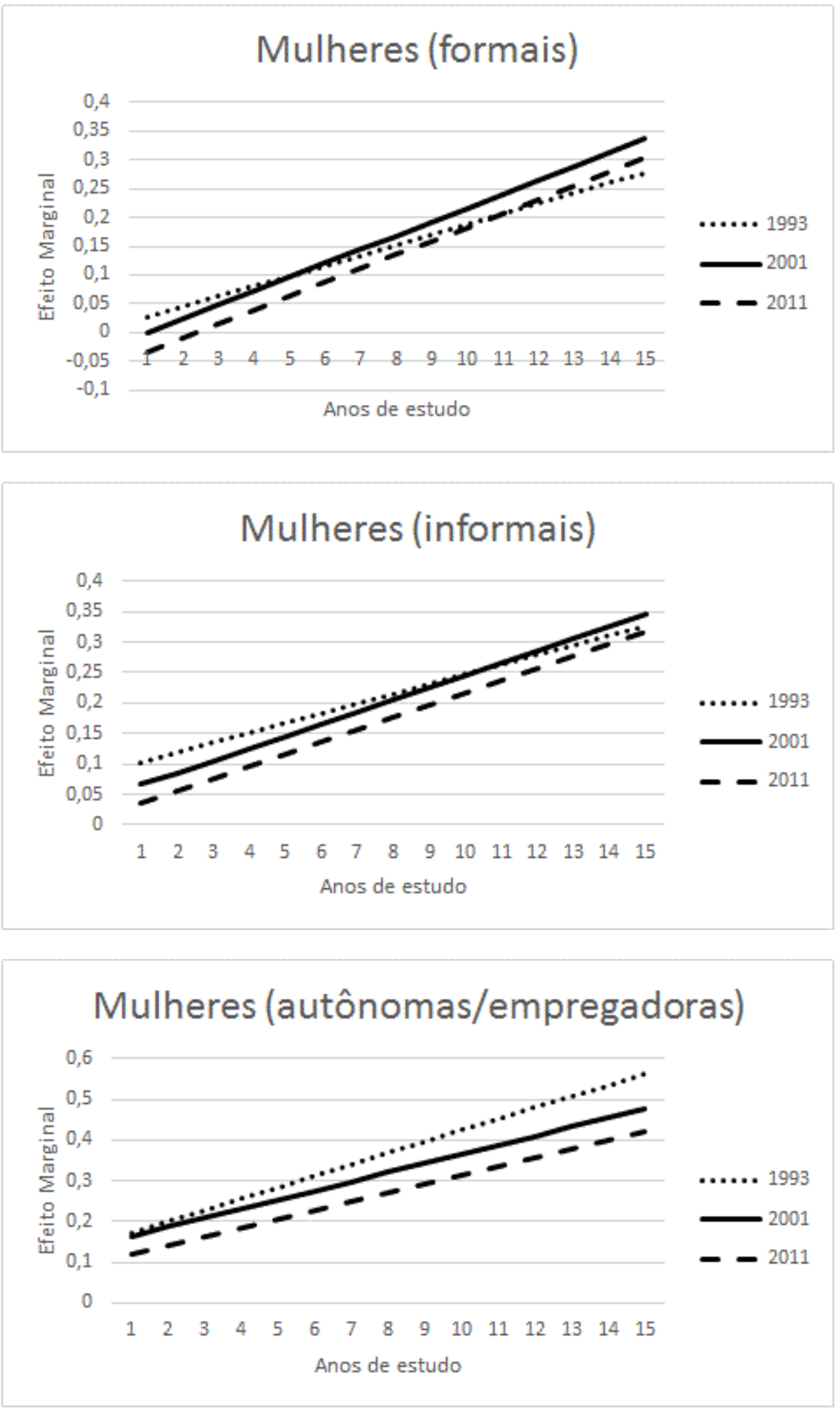
Passamos, a seguir, para os resultados referentes às equações de participação. As tabelas com os coeficientes estimados encontram-se no apêndice B. A tabela B.1 se refere à estimação para os chefes de família e a tabela B.2, para os demais membros (a estimação ocorre separadamente já que utilizamos variáveis explicativas diferentes para cada caso, como vimos na descrição da metodologia). Em ambas as tabelas, temos os resultados das opções de ocupação versus não trabalhar (inativo ou desempregado).

Na tabela B.1, para o chefe de família, vemos que para todos os setores, a maior parte dos coeficientes se mostra significativo a pelo menos 10\%. Em especial, o coeficiente relacionado à educação é significativo a 1\%, exceto em 2001 para chefes autônomos/empregadores. Na tabela B.2, participação dos demais membros, ocorre algo semelhante à estimação para os chefes de família: os coeficientes das variáveis se mostram em sua grande maioria significativos a pelo menos $10 \%$.

Para detalharmos mais, a seguir seguem as tabelas com os respectivos efeitos marginais (a média dos efeitos marginais calculados para todos os indivíduos) de cada variável sob a escolha de participação no mercado de trabalho para cada ano estudado. Na tabela 17, temos os resultados para os chefes de família. A educação possui um efeito positivo sobre a participação no mercado formal para os chefes em qualquer um dos anos (este efeito vem diminuindo com os anos) e, de maneira geral, afeta negativamente a participação nos demais setores.

Outro ponto é que a experiência parece afetar positivamente a participação como formal e autônomo/empregador, mas negativamente como informal (este último efeito elevou-se em 2011). A região urbana apresenta um impacto positivo sobre a participação dos chefes no mercado formal e negativo nos demais setores em todos os anos, ainda que a magnitude deste efeito varie entre os anos. Ser homem também impacta de forma positiva a opção por se tornar trabalhador formal ou autônomo/empregador e de forma negativa, a de se tornar informal (exatamente o que vimos na descrição dos dados anteriormente: os homens, após o mercado formal, optam em sua maioria por trabalhar como autônomo/empregador). 
O número de moradores mais novos (até 13 anos) e mais velhos (mais de 65 anos) impacta de forma negativa a participação do chefe no mercado formal em todos os anos, mas de forma positiva a participação como autônomo/empregador e este último efeito não varia muito com o tempo. Quanto à escolaridade média do domicílio, esta impacta positivamente a participação como formal e a proporção de homens, assim como a ausência de membros entre 14 e 65 anos de idade, negativamente.

Já na tabela 18, vemos os efeitos marginais para os demais membros, para todos os anos estudados. Nota-se que a educação impacta positivamente a participação no mercado formal em qualquer ano. Da mesma forma, a experiência apresenta efeito marginal positivo em todos os setores, no entanto, sua magnitude é maior que o efeito da educação. A dummy para região urbana também apresenta efeito marginal significativo e, em sua maioria, efeitos positivos na participação do membro do domicílio em qualquer atividade. Quanto à dummy para gênero: ser homem impacta de forma positiva a participação no mercado de trabalho, especialmente como formal ou autônomo/empregador. Para os demais membros, as últimas três variáveis se referem ao efeito da empregabilidade do chefe sobre a participação de outro membro no mercado de trabalho: um chefe formal impacta negativamente.

Por fim, analisaremos o efeito marginal da educação mais detalhadamente ao considerarmos as figuras 3 e 4 . Nelas estão expressos os efeitos marginais médios da educação sobre a participação no mercado de trabalho. Assim, podemos visualizar o quanto cada ano a mais de escolaridade afeta a participação em cada um dos setores ocupacionais, inclusive a opção por não trabalhar.

Observamos que a educação tem maior impacto sobre a participação no mercado de trabalho formal do que qualquer outra atividade, tanto para chefes quanto para os demais membros. Este impacto é tanto maior quanto maior o número de anos de escolaridade. No entanto, é importante notar que este efeito vem diminuindo ao longo do tempo: é menor para o ano de 2011 do que para os anos 1993 e 2001. 


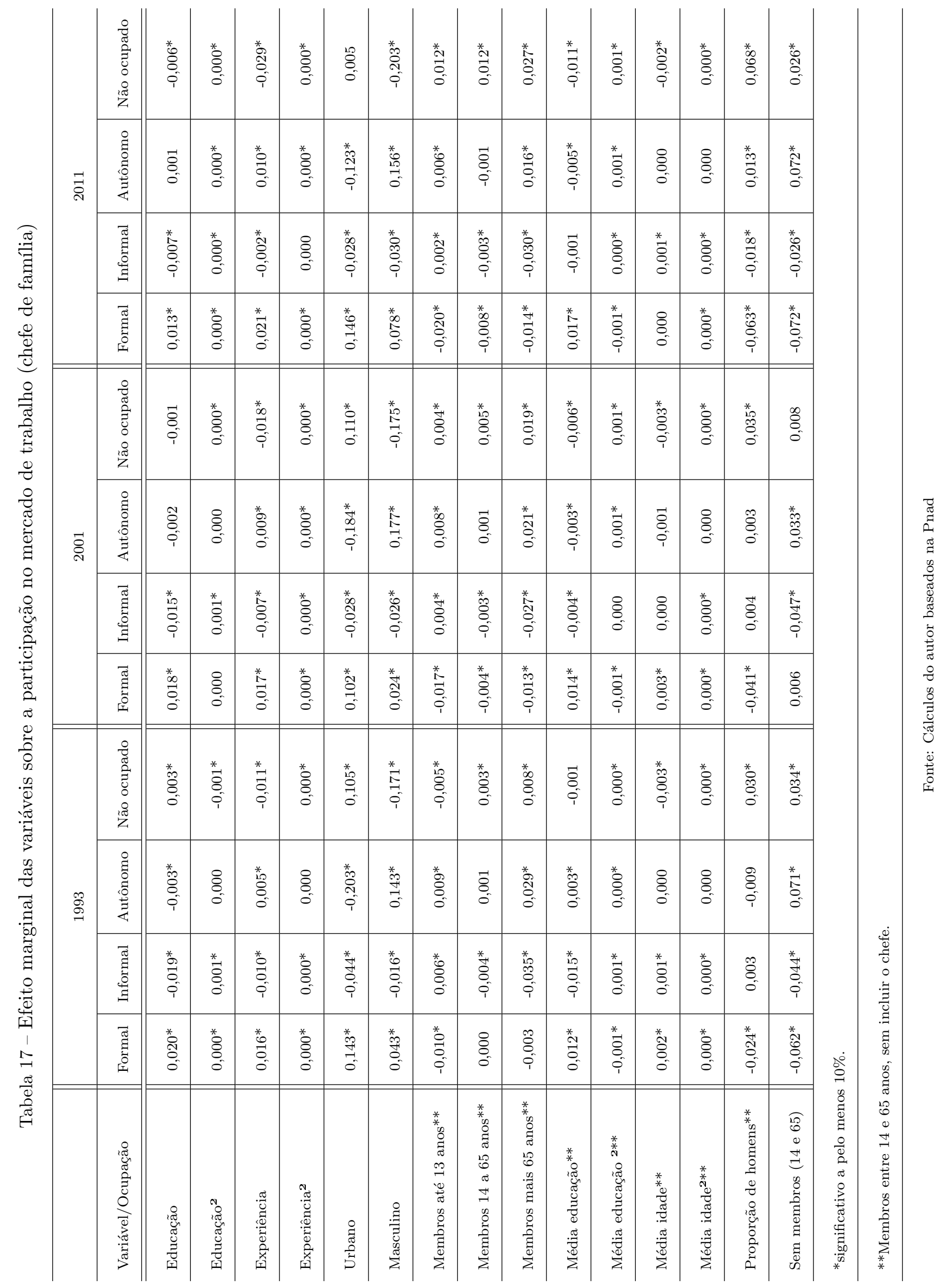




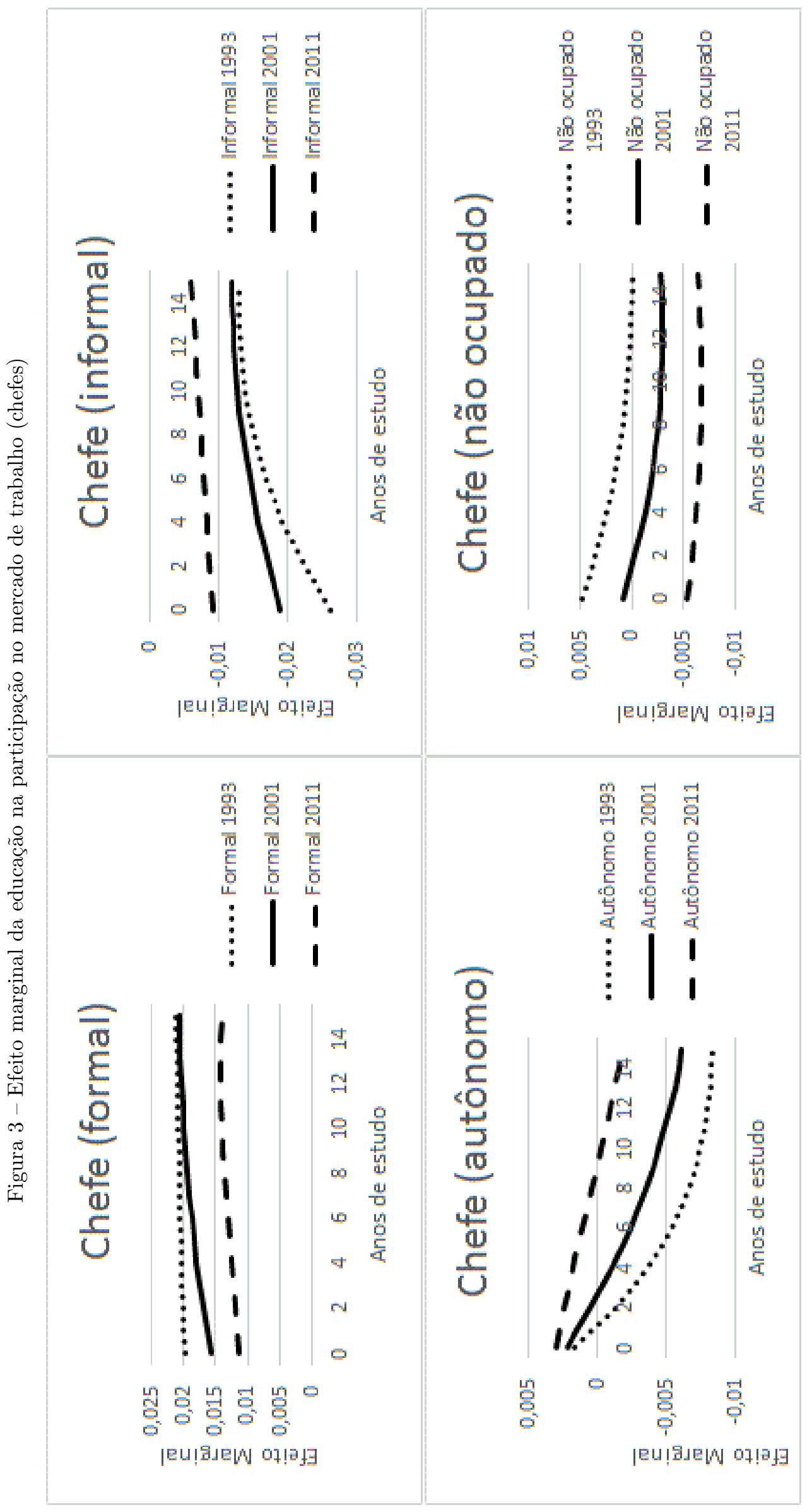




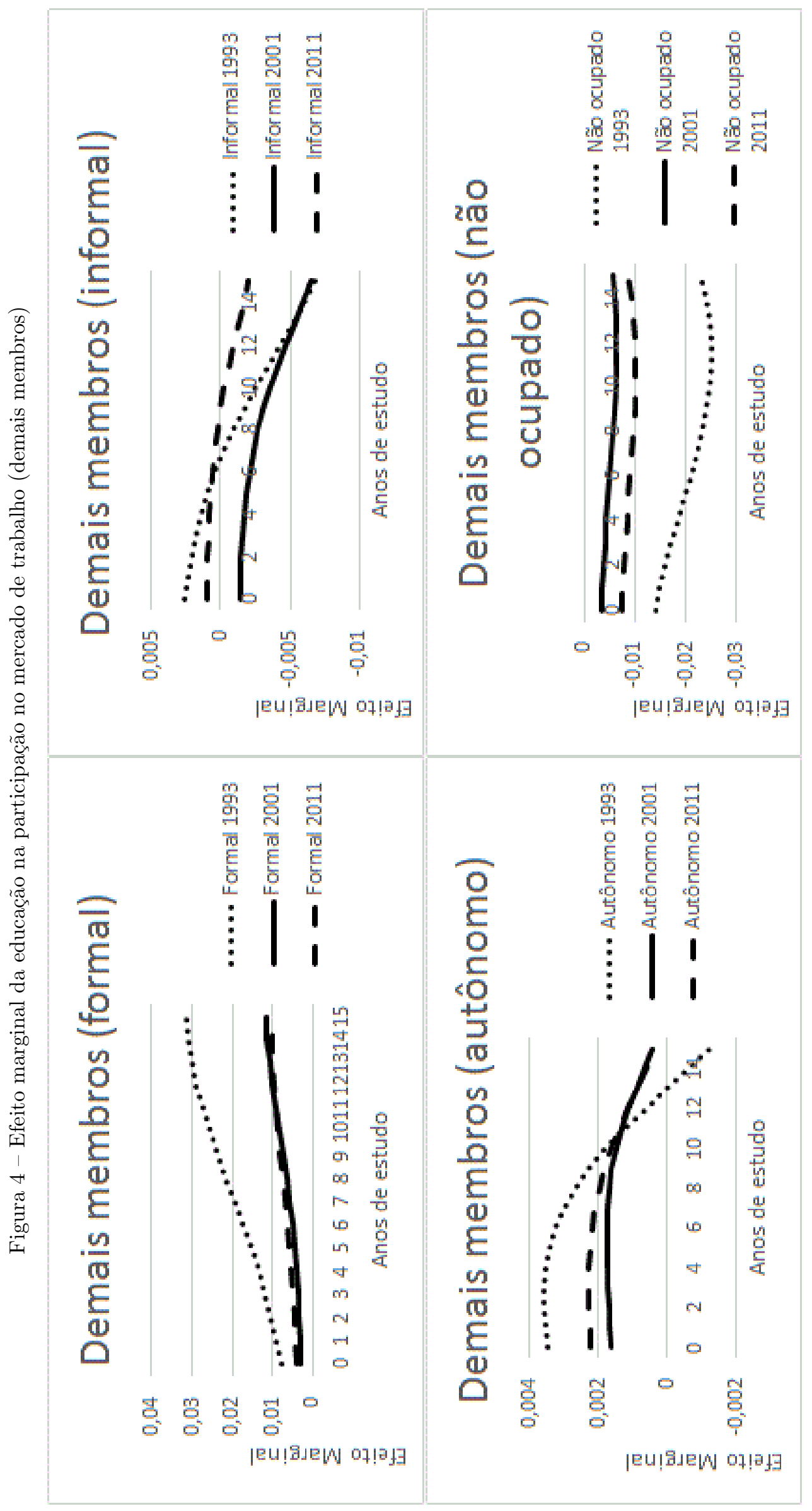




\subsection{Resultados das simulações}

Partimos, então, para a exposição dos resultados referentes às simulações realizadas. As simulações se dividem em dois grupos: efeito quantidade (anos de estudo) e efeito preço (da educação) para geração de renda. Nas simulações, substituímos a distribuição de variáveis explicativas e parâmetros estimados de 2011 nos outros anos (1993 e 2001).

\subsubsection{Efeito quantidade da educação}

Nesta simulação, impomos a distribuição da variável educação (anos de estudo) observada em 2011 nos anos de 1993 e 2001. Um primeiro resultado pode ser analisado na tabela 19: a imposição da distribuição da educação de 2011 nos demais anos resultou em um aumento da escolaridade média da população (de cerca de 5 anos em 1993 para 7,3 anos e de 6 anos em 2001 para cerca de 7,4 anos).

Já nas tabelas 20 e 21, temos a situação (observada e após simulações) da participação no mercado de trabalho. Nas tabelas 22 e 23, apresentamos a situação da renda do trabalho e por fim, na tabela 24, observamos os indicadores de pobreza e de desigualdade de renda.

Podemos verificar, na tabela 20, que as mudanças ocupacionais após a simulação são marginais. Para acompanhar a situação com mais detalhes, podemos observar a tabela 21. Nesta tabela é possível identificar como ocorre a mudança de ocupação na população após a simulação no ano de 1993: a maior parte dos indivíduos permanece em sua situação inicial e maiores mudanças são vistas para os demais membros e não tanto para os chefes.

Ainda na tabela 20, temos que a simulação da distribuição dos anos de escolaridade de 2011 nos outros anos resultou em um aumento da média da escolaridade da população tanto em 1993 quanto em 2001, provocando, assim, um aumento da porcentagem de chefes 
Tabela 19 - Média de anos de estudo - observada e após simulações (a partir da imposição da distribuição da variável em 2011)

\begin{tabular}{l||c||c||c}
\hline Média de anos de estudo & 1993 & 2001 & 2011 \\
\hline Observada & 5,10 & 6,10 & 7,43 \\
\hline Simulada & 7,29 & 7,42 & - \\
\hline
\end{tabular}

Tabela 20 - Escolha ocupacional (\%) - observada e após simulações (a partir da imposição da distribuição da variável em 2011)

Indivíduos em cada atividade (\%)

\begin{tabular}{|c|c|c|c|c|c|}
\hline \multicolumn{3}{|l|}{1993} & \multicolumn{3}{|l|}{2001} \\
\hline & Observada & Simulada & & Observada & Simulada \\
\hline \multicolumn{3}{|l|}{ Chefes } & \multicolumn{3}{|l|}{ Chefes } \\
\hline Formal & 33,92 & 33,92 & Formal & 29,78 & 29,77 \\
\hline Informal & 13,90 & 13,77 & Informal & 14,87 & 14,85 \\
\hline Autônomo/empregador & 29,32 & 29,47 & Autônomo/empregador & 28,16 & 28,21 \\
\hline Não ocupado & 22,86 & 22,84 & Não ocupado & 27,19 & 27,17 \\
\hline \multicolumn{3}{|l|}{ Demais membros } & \multicolumn{3}{|l|}{ Demais membros } \\
\hline Formal & 15,08 & 15,28 & Formal & 15,69 & 15,69 \\
\hline Informal & 12,82 & 12,65 & Informal & 12,88 & 12,70 \\
\hline Autônomo/empregador & 7,17 & 7,12 & Autônomo/empregador & 7,65 & 7,66 \\
\hline Não ocupado & 64,94 & 64,95 & Não ocupado & 63,79 & 63,95 \\
\hline
\end{tabular}

autônomos/empregadores em detrimento dos informais e uma elevação da porcentagem dos demais membros no mercado formal (em 1993) e de não ocupados (em 2001). 


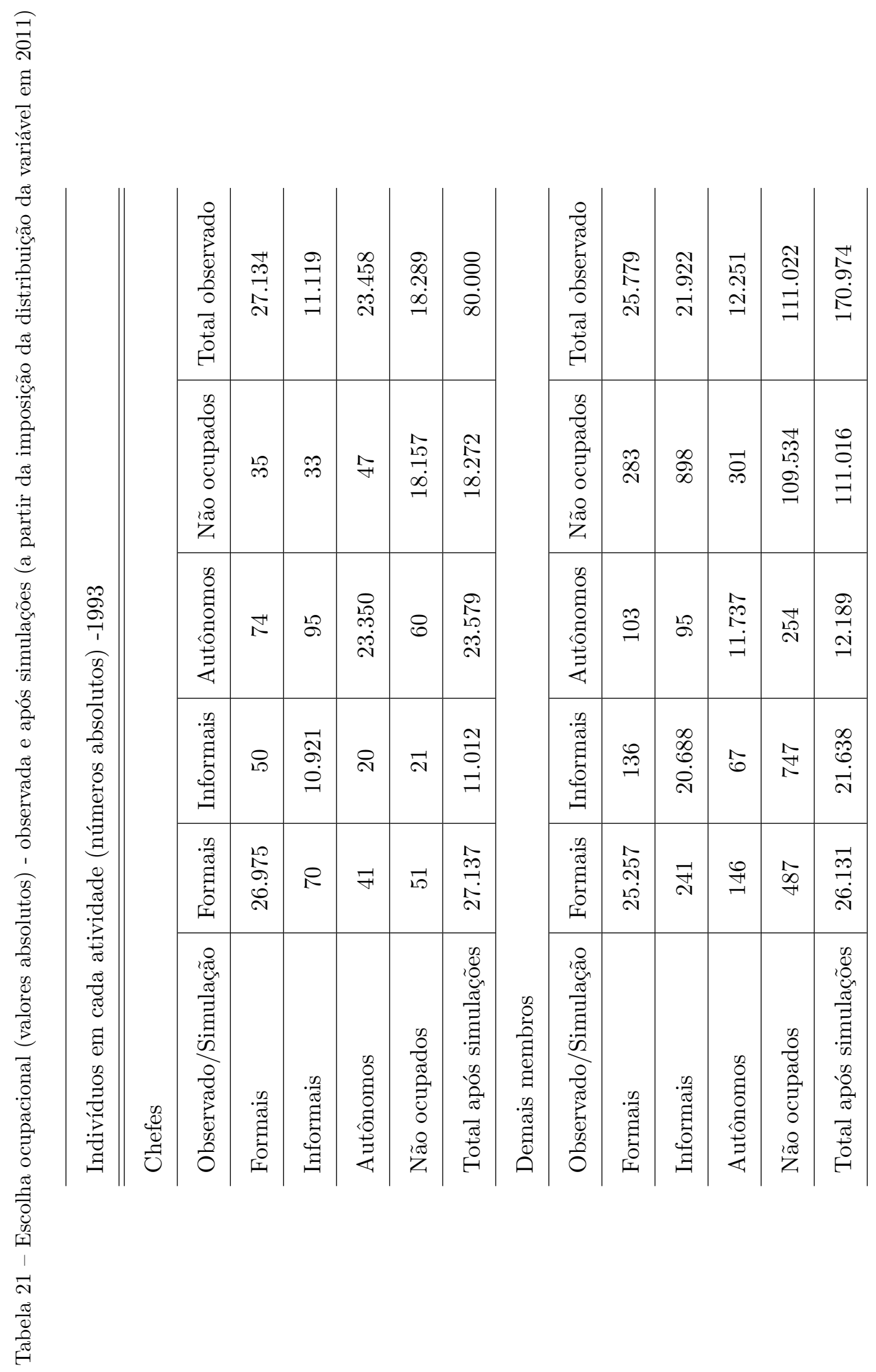


Tabela 22 - Renda média do trabalho - observada e após simulações (a partir da imposição da distribuição da variável em 2011)

\begin{tabular}{|c|c|c|c|}
\hline \multicolumn{2}{|l|}{1993} & \multicolumn{2}{|l|}{2001} \\
\hline Chefes & & Chefes & \\
\hline Observada & $1.474,63$ & Observada & $1.514,51$ \\
\hline Simulada & $1.794,48$ & Simulada & $1.715,94$ \\
\hline Demais membros & & Demais membros & \\
\hline Observada & 700,60 & Observada & 861,59 \\
\hline Simulada & 748,50 & Simulada & 850,53 \\
\hline
\end{tabular}

Na tabela 22, vemos que em ambos os anos, a simulação resultou em um aumento da renda média do trabalho para os chefes, enquanto que para os demais membros, em 1993, a renda média aumentou e em 2001 caiu. Quanto aos quartis da renda (tabela 23), vemos em 1993 que os chefes $25 \%$ mais pobres tinham uma renda de $\mathrm{R} \$ 351,72$ e após a simulação passou para $\mathrm{R} \$ 455,01$, já os demais membros $25 \%$ mais pobres passaram de $\mathrm{R} \$ 211,03$ para 138,94. Já entre os $25 \%$ mais ricos, a renda aumenta tanto para os chefes quanto para os demais membros.

Em 2001, a análise é semelhante: novamente há uma queda na renda dos demais membros mais pobres. Essa queda que ocorre na renda dos demais membros é devido à mudança de composição setorial: a população mais escolarizada deixa de trababalhar, reduzindo o rendimento médio do trabalho.

Observamos nas simulações, tanto em 1993 quanto em 2001, um aumento da renda percapita (tabela 24). Como a renda não proveniente do trabalho se mantém constante, temos que o aumento da renda per-capita é justificado pelo aumento da renda do trabalho, que ocorreu principalmente para as camadas mais pobres, o que resultou em queda da desigualdade, além da queda nos indicadores de pobreza. 


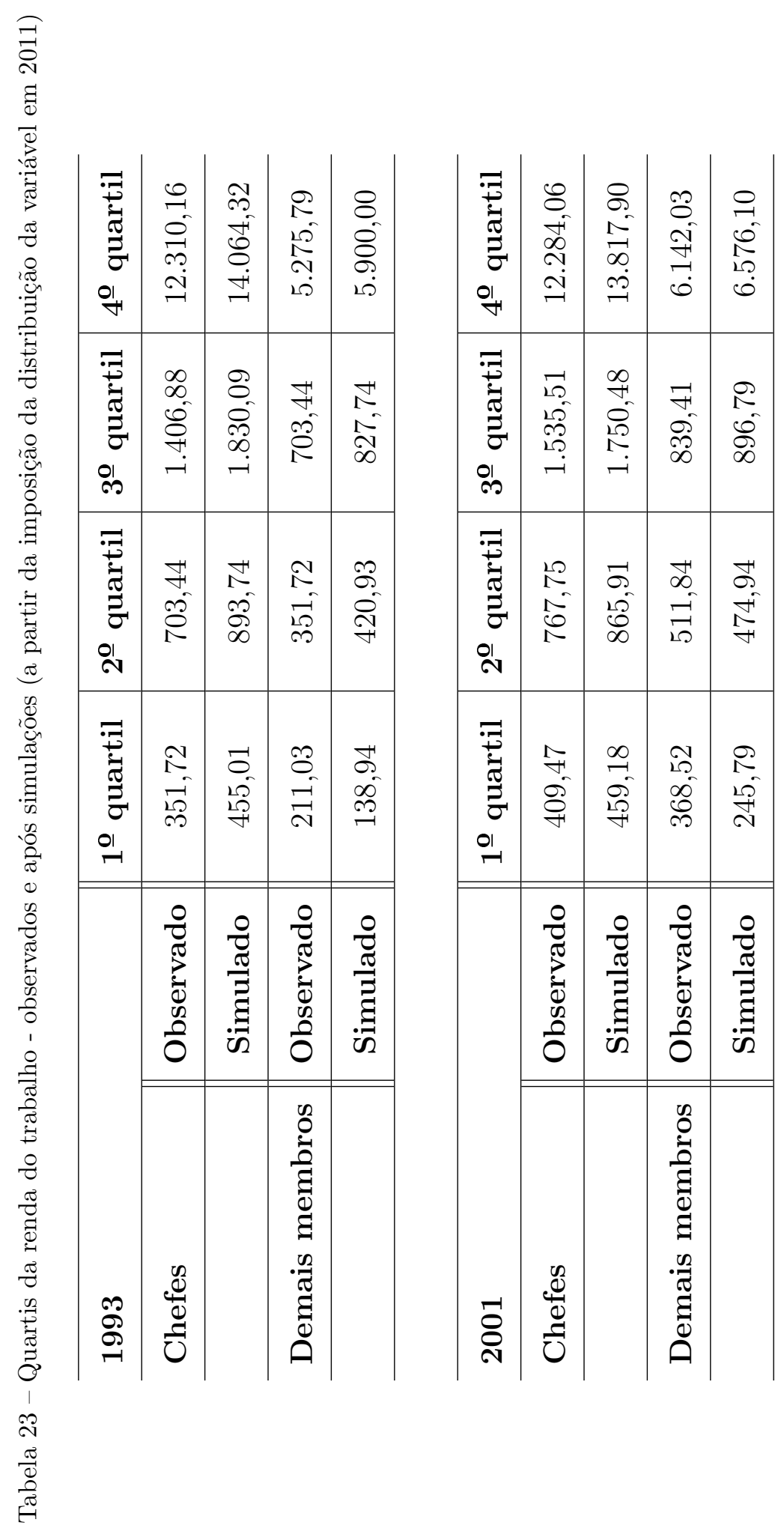




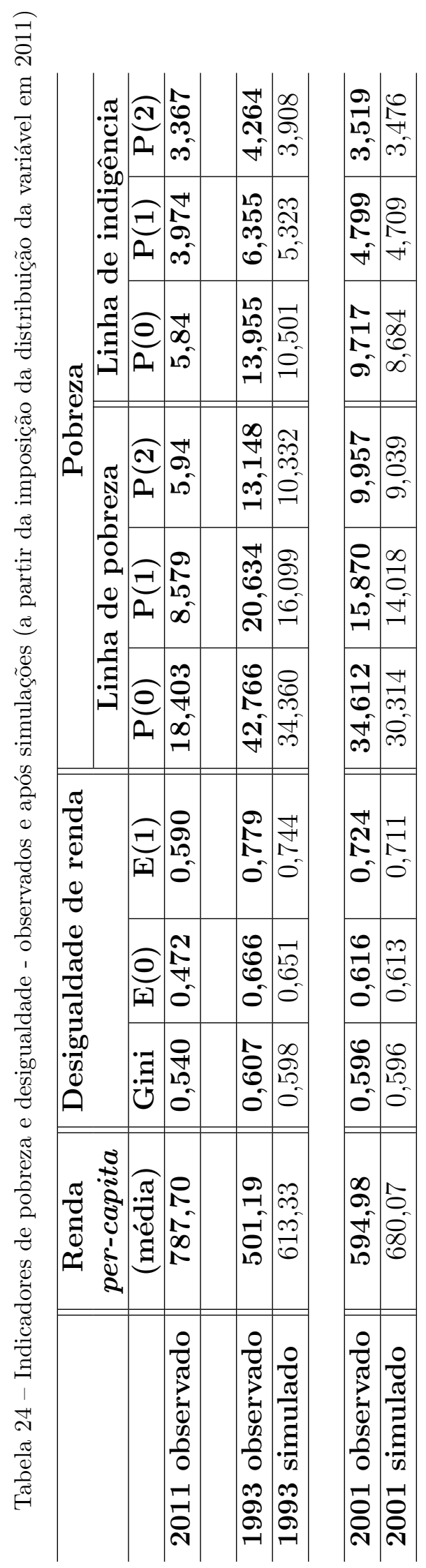


Sobre a queda na pobreza ocorrida: entre 1993 e 2011, considerando o indicador proporção de pobres, há uma redução observada de cerca de 24 pontos percentuais (pp). A simulação provocou uma redução de 8pp, ou seja, o efeito quantidade da educação em 1993 foi responsável por cerca de 34\% da queda ocorrida na pobreza no período. Já em 2001, a queda observada na pobreza até 2011 foi de cerca de 16pp, enquanto que a simulação provocou uma queda de 4,3pp, representando cerca de $27 \%$ da queda total observada entre 2001 e 2011.

Ainda na tabela 24, ao analisarmos a queda na extrema pobreza, vemos que a queda foi de 8pp de 1993 a 2011, enquanto que a simulação provocou queda de 3pp, representando $43 \%$ da queda e em 2001, a queda com a simulação foi de 1pp contra 3,9pp observados, ou seja, representando $27 \%$ da queda observada entre 2001 e 2011.

Quanto à desigualdade de renda, ao considerarmos o índice de Gini, por exemplo, a queda observada no indicador entre 1993 e 2011 foi de 0,0667 e na simulação a queda foi de 0,0087, portanto, cerca de $13 \%$ da queda na desigualdade observada no período. Já entre 2001 e 2011, a simulação do efeito quantidade da educação provocou uma queda no índice de Gini de apenas 0,0004 contra a queda observada de 0,0564, ou seja, apenas $1 \%$ da queda observada.

Notamos assim que, a simulação da distribuição da variável anos de estudo de 2011 em 1993 e 2001 provocou queda na pobreza (e extrema pobreza) e na desigualdade de renda, mas mais intensamente nos indicadores de pobreza quando comparados com os de desigualdade de renda e mais significativamente em 1993 do que em 2001. 


\subsubsection{Efeito preço da educação}

Nas simulações referentes ao efeito preço da educação, nas quais trocamos os parâmetros ß’s da educação das equações de rendimento calculados para 2011 nos anos de 1993 e 2001, temos na tabela 27 o quanto as simulações alteraram os indicadores de desigualdade de renda e pobreza quando comparamos os indicadores calculados com os dados observados. Para auxiliar a interpretação dos resultados também podemos visualizar as tabelas 25 e 26, que mostram o quanto as simulações alteraram a renda do trabalho.

Ao analisar as simulações de efeito preço nas equações de rendimentos, observamos que os resultados são muito semelhantes para 1993 e 2001: a renda do trabalho média cai (tabela 25), para todos os setores ocupacionais (formal, informal e autônomo/empregador), o que é esperado já que os efeitos marginais da educação para 2011 são menores do que os encontrados na estimação para 1993 e 2001, como vimos nas figuras 1 e 2 (exceto para os homens mais escolarizados e mulheres formais com mais anos de estudo).

Já na tabela 26, temos os quartis da renda observados e após a simulação do efeito preço da educação. Como podemos perceber, tanto em 1993 quanto em 2001, todos os quartis caem com a simulação. No entanto, as quedas forma proporcionalmente maiores em 1993, o que era esperado, uma vez que os parâmetros da educação foram diminuindo ao longo dos anos e assim, a substituição do parâmetro de 2011 é mais significativa em 1993, ano com o maior parâmetro estimado para a educação.

Na tabela 27, vemos que a renda do trabalho se reduz e, consequentemente, a renda percapita média também se reduz. A queda na renda per-capita ocorre tanto para os mais pobres (justificando um aumento da pobreza) quanto para os mais ricos. No entanto, para os mais afortunados, a queda foi maior, uma vez que a desigualdade diminuiu, quando comparada com a observada no ano considerado. Apenas para exemplificar, vemos que o coeficiente de Gini, que era de 0,607 com os dados observados em 1993 passou para 0,597 com a simulação 
Tabela 25 - Renda média do trabalho - observada e após simulações (em 1993 e 2001, usando os coeficientes da educação de 2011)

\begin{tabular}{l||c|c||c|c}
\hline Renda média do trabalho & \multicolumn{2}{||}{ Observada } & \multicolumn{2}{c}{ Após simulações } \\
\hline \hline & $\mathbf{1 9 9 3}$ & $\mathbf{2 0 0 1}$ & $\mathbf{1 9 9 3}$ & $\mathbf{2 0 0 1}$ \\
\hline Todos & $1.095,36$ & $1.195,45$ & 686,79 & 777,85 \\
\hline
\end{tabular}

Por setor

\begin{tabular}{l||c|c||c|c}
\hline Formais & $1.318,62$ & $1.390,07$ & 852,77 & 941,20 \\
\hline Informais & 438,39 & 625,86 & 265,56 & 433,96 \\
\hline Autônomos & $1.356,10$ & $1.435,20$ & 830,31 & 870,14 \\
\hline
\end{tabular}

Tabela 26 - Quartis da renda do trabalho - observados e após simulações (em 1993 e 2001, usando os coeficientes da educação de 2011)

\begin{tabular}{c||c|c|c|c}
\hline $\mathbf{1 9 9 3}$ & $\mathbf{1}^{\mathbf{0}}$ quartil & $\mathbf{2}^{\mathbf{0}}$ quartil & $\mathbf{3}^{\mathbf{o}}$ quartil & $\mathbf{4}^{\mathbf{0}}$ quartil \\
\hline Observado & 337,65 & 527,58 & $1.055,16$ & $9.496,41$ \\
\hline Simulado & 154,55 & 337,86 & 687,52 & $5.881,62$ \\
\hline \hline $\mathbf{2 0 0 1}$ & $\mathbf{1}^{\mathbf{o}}$ quartil & $\mathbf{2}^{\mathbf{0}}$ quartil & $\mathbf{3}^{\mathbf{o}}$ quartil & $\mathbf{4}^{\mathbf{0}}$ quartil \\
\hline Observado & 368,52 & 614,20 & $1.228,41$ & $10.236,71$ \\
\hline Simulado & 232,20 & 422,70 & 818,02 & $6.614,22$ \\
\hline
\end{tabular}

e em 2001, o observado era no valor de 0,596 e com a simulação passou para 0,578.

Mais detalhadamente, temos que em relação à desigualdade de renda, ao considerarmos o índice de Gini, por exemplo, a queda observada no indicador entre 1993 e 2011 foi de 0,0667 e na simulação a queda foi de 0,010, portanto, cerca de $15 \%$ da queda na desigualdade observada no período. Já entre 2001 e 2011, a simulação do efeito preço da educação provocou uma queda no índice de Gini ainda maior, de 0,018 ou seja, 33\% da queda observada. 


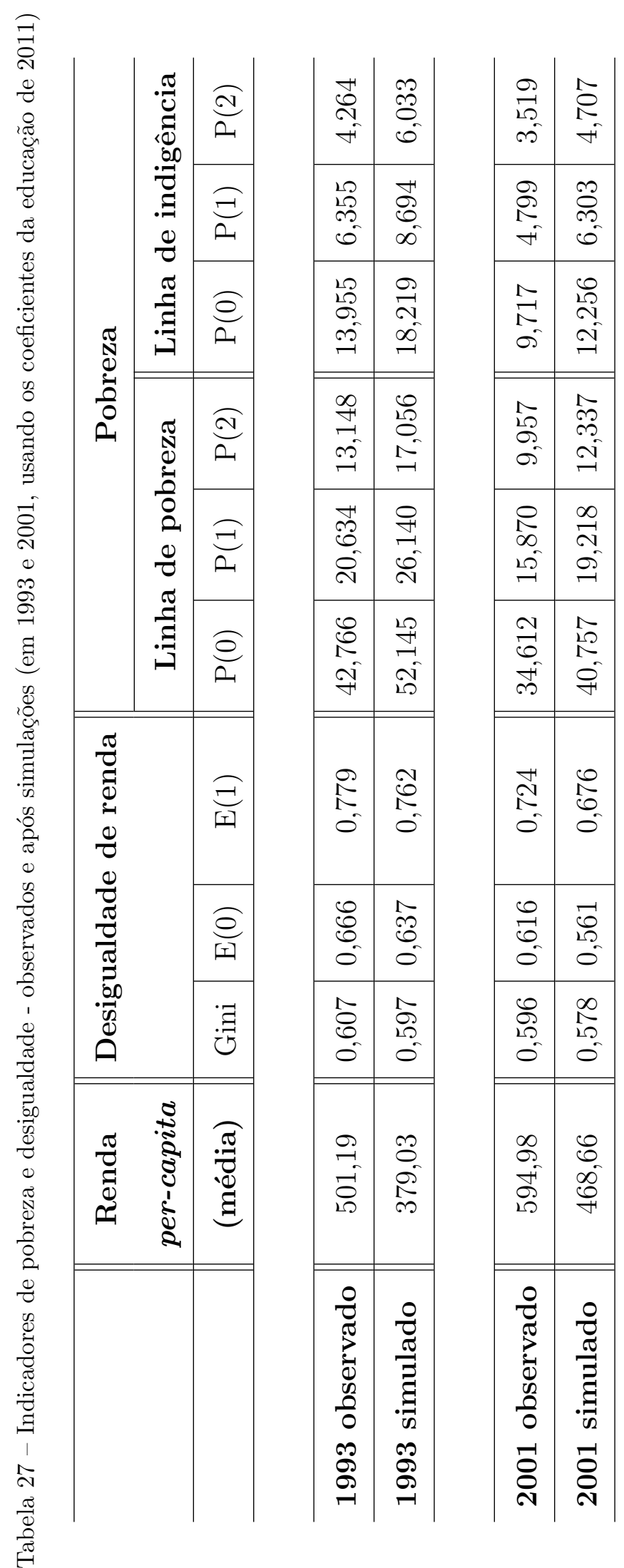


É importante destacar que nossa metodologia quer isolar o efeito preço da educação, o que implica em manter tudo o mais constante. Com essa decisão, temos que a simulação do efeito marginal da educação de 2011 nos outros anos acaba por impor um retorno menor da educação sobre a formação da renda, sem alterar a "quantidade" da educação. Ou seja, ao realizarmos essa estática comparativa, reduzimos o preço sem aumentar a oferta da educação. Uma provável consequência é que ao fazermos isso, o salário dos menos escolarizados não se altera muito com a simulação (afinal a mudança ocorre no preço de um "bem" que estes indivíduos não possuem em abundância), mas em um cenário real esperaríamos que o salário dos poucos qualificados também aumentasse com a queda no efeito preço da educação. Essa é a explicação que encontramos para o resultado contra-intuitivo em que os indicadores de pobreza se elevam após a simulação. 


\subsubsection{Resumo das simulações}

Os resultados das simulações apresentados anteriormente indicam que tanto o efeito preço quanto o efeito quantidade da educação afetam a desigualdade de renda (de forma a reduzir os indicadores que mensuram este fenômeno), mas somente o efeito quantidade parece ter afetado a redução da pobreza, nos períodos analisados.

Com relação ao efeito quantidade da educação, temos que ao imputar a distribuição da variável "anos de estudo" de 2011 nos anos de 1993 e 2001, houve uma queda não só nos indicadores de desigualdade de renda como também nos indicadores referentes à pobreza e extrema pobreza.

A educação explica 34\% da queda no indicador de proporção de pobres entre 1993 e 2011, 43\% da queda na proporção de extremamente pobres e $13 \%$ da queda no Gini (desigualdade de renda) no mesmo período. Já para os anos entre 2001 e 2011, o efeito quantidade da educação explica $27 \%$ da queda na proporção de pobres e de extremamente pobres e apenas $1 \%$ da queda na desigualdade de renda ocorrida entre estes anos.

Assim, o impacto do efeito quantidade da educação é maior nos indicadores de pobreza do que nos indicadores de desigualdade. Além disso, o impacto também é maior quando consideramos o período entre 1993 e 2011 do que entre os anos de 2001 e 2011.

Considerando a simulação que captura o efeito preço da educação, temos que o impacto foi no sentido de reduzir a renda do trabalho e, por consequência, a renda per-capita. Esta queda é devido à diminuição do efeito marginal da educação na formação da renda (como destacado na exposição dos resultados da estimação do modelo) e ocorre tanto para os mais pobres (justificando um aumento da pobreza) quanto para os mais ricos. No entanto, para estes últimos, esta queda é maior, o que provocou queda na desigualdade de renda: o efeito preço da educação explica 15\% da queda observada entre 1993 e 2011 e $33 \%$ da queda ocorrida entre 2001 e 2011. 
Ainda sobre a simulação do efeito preço, cabe reforçar que quando realizamos um exercício de estática comparativa, mantemos todas as demais variáveis constantes, ou seja, no nosso caso, reduzimos o preço sem aumentar a oferta da educação. Uma provável consequência é que ao fazermos isso, o salário dos menos escolarizados não se altera muito com a simulação, mas em um cenário real esperaríamos que o salário dos poucos qualificados também aumentasse com a queda no efeito preço da educação. Essa seria a explicação encontrada para o resultado contra-intuitivo em que os indicadores de pobreza se elevam após esta simulação.

Podemos comparar estes resultados com os divulgados em [Ferreira e Barros 1999], que aplica metodologia semelhane a desse estudo. No artigo, simulam-se as características de 1996 em 1976, 1981 e 1985. Assim como neste trabalho, os resultados do artigo mostraram que o impacto do efeito preço é no sentido de reduzir a desigualdade de renda e o efeito quantidade afeta de forma a reduzir tanto pobreza quanto desigualdade de renda. Para ilustrar, um exemplo: o efeito preço da educação resultou em uma queda no Gini de 0,595 (observado em 1976) para 0,593, sendo que o valor observado em 1996 era de 0,591.

Outro ponto interessante está em considerar o impacto de ambos os efeitos da educação, realizando as simulações simultaneamente, ou seja, alterar não somente a distribuição da variável "anos de estudo" como também os parâmetros da educação nas equações de rendimento. Os resultados para esta simulação não são apresentados neste trabalho, mas comentamos resumidamente que esta simulação intensificou o impacto da educação na redução da desigualdade de renda, nos períodos considerados, o que era esperado: ambas as simulações isoladamente também reduziram a desigualdade de renda.

Este estudo corrobora com a revisão da literatura bibliográfica apresentada na seção 2 destes estudo: a educação parece desempenhar um resultado muito significativo no cenário recente de menor desigualdade de renda e pobreza no Brasil, no entanto, não está sozinha. São diversos os fatores que influenciaram essa melhoria socioeconômica, como por exemplo, aumentos reais nos valores do salário mínimo e as transferências de renda governamentais, como indicam os artigos [Firpo e Reis 2007] e [Soares et al. 2006], respectivamente. 


\section{Conclusões}

Este trabalho teve como objetivo avaliar o impacto da educação da população sobre a distribuição de renda no Brasil para o período de 1993 a 2011. Para tanto, elaborou-se um modelo de formação de renda e realizaram-se micro-simulações de forma a capturar o efeito dos anos de escolaridade do indivíduo sobre a sua participação no mercado de trabalho e sobre sua renda.

Antes de analisarmos os resultados das simulações, é importante destacar alguns dos resultados provenientes da estimação do modelo proposto neste trabalho. Com relação à estimação da equação de participação, os coeficientes se mostraram majoritariamente significativos e o efeito marginal da educação se mostrou positivo para o trabalho no setor formal, no caso dos chefes e em qualquer dos setores ocupacionais, para os demais membros.

Em sua grande maioria, os coeficientes estimados para as equações de rendimentos se mostraram significativos e com os sinais esperados, tanto para homens quanto para mulheres, em todos os anos. Especificamente, para os coeficientes da educação observamos que seus valores vêm diminuindo ao longo dos anos, principalmente em 2011, revelando uma queda recente do efeito marginal da educação sobre a formação da renda das pessoas. Enfatizamos também a significância da razão inversa de Mills, reforçando a suposição de viés de seleção, para o caso das mulheres.

Considerando os resultados para as simulações realizadas, temos resultados distintos para cada caso (efeito preço e efeito quantidade). Na simulação do efeito quantidade, temos que a imputação da distribuição da variável "anos de estudo" em 2011 nos anos de 1993 e 2001 resultou em queda tanto nos indicadores de desigualdade de renda quanto nos indicadores de pobreza/extrema pobreza. 
Os resultados desta simulação (efeito quantidade) indicam que a educação explica 34\% da queda no indicador de proporção de pobres entre 1993 e 2011, 43\% da queda na proporção de extremamente pobres e $13 \%$ da queda no Gini (desigualdade de renda) no mesmo período. Para os anos entre 2001 e 2011, o efeito quantidade da educação explica 27\% da queda na proporção de pobres e de extremamente pobres e apenas $1 \%$ da queda na desigualdade de renda ocorrida no período analisado.

Na simulação do efeito preço (na qual substituímos os coeficientes da educação e educação ao quadrado de 2011 em 1993 e em 2001), observamos que a renda do trabalho e a renda percapita caem. Esta queda é devido à diminuição do efeito marginal da educação na formação da renda e ocorre tanto para os mais pobres (justificando um aumento da pobreza) quanto para os mais ricos. No entanto, para estes últimos, esta queda é maior, o que provoca queda na desigualdade de renda, quando comparada com a observada em cada ano considerado: o efeito preço da educação explica 15\% da queda observada entre 1993 e 2011 e 33\% da queda ocorrida entre 2001 e 2011.

Concluímos assim que este estudo corrobora a literatura bibliográfica discutida anteriormente: ainda que outros fatores (por exemplo, aumento real no salário mínimo e transferências de renda pelo governo) também tenham provocado a redução da pobreza e desigualdade de renda neste período recente da história do Brasil, o impacto da educação foi muito significativo, exatamente o que este presente trabalho buscou demonstrar. Para ilustrar, considerando que o efeito quantidade da educação foi responsável por $13 \%$ da queda no Gini ocorrida entre 1993 e 2011 e a escolaridade média passou de 5,1 para 7,3 com a simulação (ou seja, aumentou 2,2 anos) então, na média cada ano de escolaridade reduziu em $6 \%$ a desigualdade de renda. A partir de uma extrapolação simples, para garantir um indíce de Gini igual ao da média dos países da OCDE (0,32 em 2011), seria necessário aumentar a escolaridade média da população (observada em 2011) em 7 anos, passando de 7,4 para 14,4. 


\section{Referências}

[Barros et al. 2010]BARROS, R. et al. Determinantes da queda na desigualdade de renda no Brasil. [S.l.]: Ipea, 2010.

[Barros, Corseuil e Leite 1999]BARROS, R. P. d.; CORSEUIL, C. H.; LEITE, P. G. Labor market and poverty in brazil. Brazilian Review of Econometrics, v. 19, n. 2, p. 297-365, 1999.

[Barros, Foguel e Ulyssea 2006]BARROS, R. P. d.; FOGUEL, M. N.; ULYSSEA, G. Desigualdade de renda no brasil: uma análise da queda recente. In: Desigualdade de renda no Brasil: uma análise da queda recente. [S.1.]: Ipea, 2006.

[Barros, Franco e Mendonça 2007]BARROS, R. P. d.; FRANCO, S.; MENDONÇA, R. Discriminação e segmentação no mercado de trabalho e desigualdade de renda no brasil. Instituto de Pesquisa Econômica Aplicada (Ipea), 2007.

[Barros, Henriques e Mendonça 2001]BARROS, R. P. de; HENRIQUES, R.; MENDONÇA, R. A estabilidade inaceitável: desigualdade e pobreza no Brasil. [S.1.]: Ipea, 2001.

[Bourguignon, Fournier e Gurgand 1979]BOURGUIGNON, F.; FOURNIER, M.; GURGAND, M. Distribution, development and education: Taiwan, 1979-1994. Development and Education: Taiwan, v. 1994, 1979.

[Bourguignon, Lustig et al. 2005]BOURGUIGNON, F.; LUSTIG, N. C. et al. The microeconomics of income distribution dynamics in East Asia and Latin America. [S.1.]: World Bank Publications, 2005.

[Fernandes, Pazello e Felicio 2002]FERNANDES, R.; PAZELLO, E.; FELICIO, F. d. A importância da estrutura familiar e do engajamento no mercado de trabalho na determinação da pobreza no brasil. Pesquisa e planejamento econômico, v. 32, n. 2, p. 233-250, 2002.

[Ferreira e Barros 1999]FERREIRA, F. H.; BARROS, R. P. de. The slippery slope: explaining the increase in extreme poverty in urban Brazil, 1976-1996. [S.l.]: World Bank Publications, 1999.

[Fields e Soares 2004]FIELDS, G. S.; SOARES, S. The microeconomics of changing income distribution in malaysia. Microeconomics of income distribution dynamics in East Asia and Latin America, 2004. 
[Firpo e Reis 2007]FIRPO, S.; REIS, M. C. O salário mínimo ea queda recente da desigualdade no brasil. Desigualdade de renda no Brasil: uma análise da queda recente, v. 2, 2007.

[Langoni 1974]LANGONI, C. G. Distribuição de renda: resumo da evidência. Fundação Getulio Vargas, 1974.

[LEONE, MAIA e BALTAR 2010]LEOnE, E. T.; MAIA, A. G.; BALTAR, P. E. Mudanças na composição das famílias e impactos sobre a redução da pobreza no brasil. Economia $e$ Sociedade, SciELO Brasil, v. 19, n. 1, p. 59-77, 2010.

[Leone, Maia e Baltar 2010]LEONE, E. T.; MAIA, A. G.; BALTAR, P. E. Mudanças na composição das famílias e impactos sobre a redução da pobreza no brasil. Economia $e$ Sociedade, SciELO Brasil, v. 19, n. 1, p. 59-77, 2010.

[Lisboa e Menezes-Filho 2001]LISBOA, M. de B.; MENEZES-FILHO, N. A. Microeconomia e sociedade no Brasil. [S.1.]: Contra Capa, 2001.

[Menezes-Filho, Fernandes e Pichetti 2007]MENEZES-FILHO, N.; FERNANDES, R.; PICHETTI, P. Educação e queda recente da desigualdade no brasil. no livro Desigualdade de Renda no Brasil: uma análise da queda Recente, organizado por Ricardo Paes e Barros, Miguel Nathan Foguel e Gabriel Ulyssea, capitulo, v. 25, p. 285-304, 2007.

[Menezes-Filho 2001]MENEZES-FILHO, N. A. A evolução da educação no brasil e seu impacto no mercado de trabalho. FEA/USP, 2001.

[Ney e Hoffmann 2008]NEY, M. G.; HOFFMANN, R. A contribuição das atividades agrícolas e não-agrícolas para a desigualdade de renda no brasil rural. Economia Aplicada, SciELO Brasil, v. 12, n. 3, p. 365-393, 2008.

[Reis e Barros 1991]REIS, J. G. Almeida dos; BARROS, R. Paes de. Wage inequality and the distribution of education: A study of the evolution of regional differences in inequality in metropolitan brazil. Journal of Development Economics, Elsevier, v. 36, n. 1, p. 117-143, 1991.

[Rocha 2003]ROCHA, S. Pobreza no Brasil: afinal, de que se trata? [S.l.]: FGV Editora, 2003.

[Soares et al. 2006]SOARES, F. V. et al. Programas de transferência de renda no brasil: impactos sobre a desigualdade. Instituto de Pesquisa Econômica Aplicada (Ipea), 2006.

[Vélez et al. 2005]VÉLEZ, C. E. et al. The reversal of inequality trends in colombia, 197895: A combination of persistent and fluctuating forces. The microeconomics of income 
distribution dynamics in East Asia and Latin America, Washington, DC: World Bank, 2005. 



\section{APÊNDICE}

\section{Apêndice A - Equações de rendimento (mulheres)}

Tabela A.1 - Equação de rendimentos: Regressão* para todas as mulheres (Heckman)

\begin{tabular}{l|c|c|c}
\hline Variável/Ano & 1993 & 2001 & 2011 \\
\hline \hline
\end{tabular}

(A) Principal

\begin{tabular}{l|c|c|c|c|c|c}
\hline & Coeficiente & p-valor & Coeficiente & p-valor & Coeficiente & p-valor \\
\hline Educação & 0,100 & 0,000 & 0,058 & 0,000 & 0,009 & 0,028 \\
\hline Educação $^{2}$ & 0,006 & 0,000 & 0,010 & 0,000 & 0,010 & 0,000 \\
\hline Experiência $_{\text {Experiência }}^{2}$ & 0,190 & 0,000 & 0,241 & 0,000 & 0,191 & 0,000 \\
\hline Urbano $^{\prime}$ & $-0,002$ & 0,000 & $-0,003$ & 0,000 & $-0,002$ & 0,000 \\
\hline Intercepto & 0,758 & 0,000 & 0,738 & 0,000 & 0,766 & 0,000 \\
\hline Razão inversa de Mills & $-0,385$ & 0,085 & $-1,553$ & 0,000 & 0,147 \\
\hline
\end{tabular}

(B) Seleção

\begin{tabular}{|c|c|c|c|c|c|c|}
\hline & Coeficiente & $\mathrm{p}$-valor & Coeficiente & $\mathrm{p}$-valor & Coeficiente & p-valor \\
\hline Educação & $-0,006$ & 0,063 & 0,005 & 0,082 & 0,018 & 0,000 \\
\hline Educação $^{2}$ & 0,006 & 0,000 & 0,006 & 0,000 & 0,005 & 0,000 \\
\hline Experiência & 0,123 & 0,000 & 0,143 & 0,000 & 0,155 & 0,000 \\
\hline Experiência $^{2}$ & $-0,002$ & 0,000 & $-0,002$ & 0,000 & $-0,002$ & 0,000 \\
\hline Urbano & 0,296 & 0,000 & 0,305 & 0,000 & 0,356 & 0,000 \\
\hline $\begin{array}{l}\text { Renda do domicílio deduzida } \\
\text { da renda da mulher (instrumento) }\end{array}$ & $-0,00002$ & 0,000 & $-0,00003$ & 0,000 & $-0,00002$ & 0,000 \\
\hline Intercepto & $-2,808$ & 0,000 & $-3,297$ & 0,000 & $-3,628$ & 0,000 \\
\hline
\end{tabular}

\begin{tabular}{l|c|c|c}
\hline № censuradas & 83.187 & 98.500 & 85.757 \\
\hline № não censuradas & 42.012 & 55.674 & 59.607 \\
\hline № observações & 125.199 & 154.174 & 145.364 \\
\hline
\end{tabular}

*Regressões ponderadas para a população. 


\section{Apêndice B - Equações de participação (logit multinomial)}

Seguem as tabelas A.1 e A.2 com os resultados das estimações para as equações de participação. É importante ressaltar que as regressões estão ponderadas para a população. 


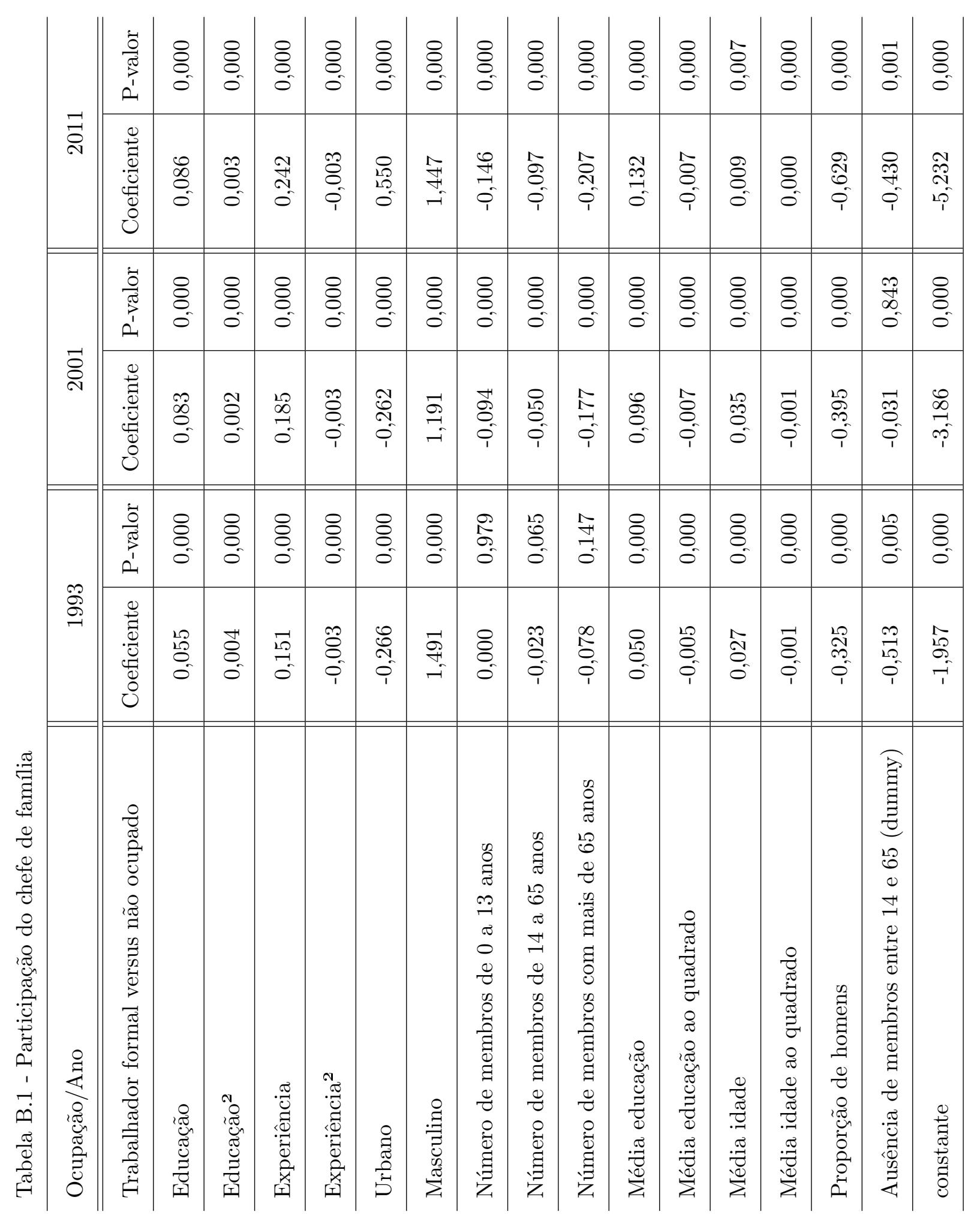




\begin{tabular}{|c|c|c|c|c|c|c|c|c|c|c|c|c|c|c|c|c|c|}
\hline \multirow{2}{*}{$\overrightarrow{\widetilde{N}}$} & 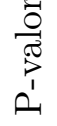 & $\begin{array}{l}\mathscr{8} \\
\stackrel{8}{0} \\
0\end{array}$ & $\begin{array}{l}8 \\
8 \\
0 \\
0\end{array}$ & $\begin{array}{l}8 \\
8 \\
0 \\
0\end{array}$ & $\begin{array}{l}8 \\
\delta \\
0\end{array}$ & $\begin{array}{l}8 \\
\delta \\
0\end{array}$ & $\stackrel{8}{8}$ & $\begin{array}{l}8 \\
8 \\
ᄋ\end{array}$ & $\begin{array}{l}8 \\
8 \\
8\end{array}$ & $\begin{array}{l}8 \\
\wp \\
ᄋ\end{array}$ & $\begin{array}{l}8 \\
8 \\
0 \\
0\end{array}$ & $\begin{array}{l}8 \\
8 \\
0 \\
0\end{array}$ & $\stackrel{8}{8}$ & $\begin{array}{l}8 \\
8 \\
\varnothing \\
0\end{array}$ & $\begin{array}{l}8 \\
\& \\
ᄋ\end{array}$ & $\stackrel{\overrightarrow{8}}{8}$ & $\begin{array}{l}8 \\
8 \\
ᄋ\end{array}$ \\
\hline & 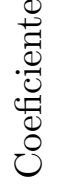 & $\begin{array}{l}\infty \\
\stackrel{N}{0} \\
0 \\
0 \\
\end{array}$ & $\begin{array}{l}\mathscr{Q} \\
\stackrel{\delta}{\delta} \\
0\end{array}$ & $\begin{array}{l}0 \\
\stackrel{-}{2} \\
0\end{array}$ & $\begin{array}{l}\stackrel{1}{8} \\
\stackrel{0}{0} \\
\end{array}$ & $\begin{array}{l}\stackrel{2}{\rho} \\
\stackrel{N}{0} \\
\tilde{\rho}\end{array}$ & $\begin{array}{l}\infty \\
\infty \\
\infty \\
0\end{array}$ & $\begin{array}{l}0 \\
\stackrel{2}{0} \\
0 \\
0 \\
1\end{array}$ & $\begin{array}{l}8 \\
\stackrel{8}{0} \\
0 \\
0\end{array}$ & 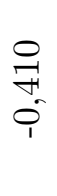 & $\begin{array}{l}\text { D. } \\
\stackrel{10}{0} \\
0\end{array}$ & $\begin{array}{l}20 \\
8 \\
0 \\
0 \\
0\end{array}$ & $\begin{array}{l}\stackrel{\overbrace{}}{0} \\
\stackrel{0}{0}\end{array}$ & $\begin{array}{l}-0 \\
8 \\
0 \\
0 \\
1\end{array}$ & $\begin{array}{l}0 \\
\text { in } \\
\text { in } \\
\text { in }\end{array}$ & $\begin{array}{l}\stackrel{+}{0} \\
\stackrel{+}{1} \\
0 \\
\end{array}$ & 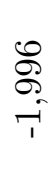 \\
\hline \multirow{2}{*}{ 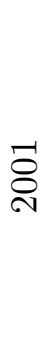 } & 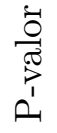 & $\begin{array}{l}8 \\
8 \\
0\end{array}$ & $\begin{array}{l}8 \\
8 \\
0 \\
0\end{array}$ & $\begin{array}{l}8 \\
8 \\
0 \\
0\end{array}$ & $\begin{array}{l}8 \\
8 \\
0\end{array}$ & $\begin{array}{l}8 \\
8 \\
\\
0\end{array}$ & $\begin{array}{l}8 \\
\stackrel{8}{8}\end{array}$ & $\begin{array}{l}\stackrel{\Omega}{1} \\
\text { o. } \\
0\end{array}$ & $\begin{array}{l}8 \\
8 \\
8\end{array}$ & $\begin{array}{l}8 \\
\stackrel{8}{8}\end{array}$ & $\begin{array}{l}2 \\
\text { ñ } \\
\text { in } \\
0\end{array}$ & $\begin{array}{l}8 \\
8 \\
0 \\
0\end{array}$ & $\begin{array}{l}8 \\
\stackrel{8}{8}\end{array}$ & $\begin{array}{l}8 \\
8 \\
8 \\
0\end{array}$ & \begin{tabular}{l}
8 \\
$\&$ \\
\hdashline
\end{tabular} & $\begin{array}{l}\tilde{8} \\
\stackrel{8}{0}\end{array}$ & $\begin{array}{l}12 \\
8 \\
0 \\
0\end{array}$ \\
\hline & 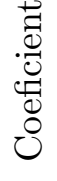 & $\begin{array}{l}\vec{J} \\
\text { O. } \\
0 \\
0\end{array}$ & $\begin{array}{l}1 \\
8 \\
0 \\
0\end{array}$ & $\begin{array}{l}10 \\
8 \\
0 \\
0\end{array}$ & $\begin{array}{l}\sigma \\
8 \\
0 \\
0\end{array}$ & $\begin{array}{l}0 \\
\infty \\
\infty \\
\infty \\
0 \\
0\end{array}$ & $\begin{array}{l}\Gamma \\
\infty \\
0 \\
0\end{array}$ & $\begin{array}{l}8 \\
\stackrel{8}{8} \\
0\end{array}$ & $\begin{array}{l}0 \\
10 \\
0 \\
0 \\
0 \\
1\end{array}$ & $\begin{array}{l}0 \\
0 \\
0 \\
0 \\
0\end{array}$ & $\stackrel{m}{0}$ & $\begin{array}{l}\delta_{0} \\
8 \\
0 \\
0\end{array}$ & $\begin{array}{l}\stackrel{L}{\stackrel{D}{0}} \\
\stackrel{0}{0}\end{array}$ & $\begin{array}{l}0 \\
8 \\
0 \\
0 \\
1\end{array}$ & 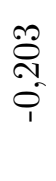 & 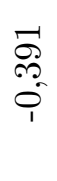 & $\begin{array}{l}\mathbb{S}_{+} \\
\stackrel{0}{0}\end{array}$ \\
\hline \multirow{2}{*}{$\begin{array}{l}\mathscr{2} \\
\mathscr{2}\end{array}$} & 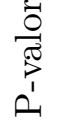 & $\begin{array}{l}8 \\
8 \\
8 \\
0\end{array}$ & $\begin{array}{l}8 \\
8 \\
0 \\
0\end{array}$ & $\begin{array}{l}0 \\
0 \\
0 \\
0\end{array}$ & $\begin{array}{l}8 \\
8 \\
0 \\
0\end{array}$ & $\begin{array}{l}8 \\
8 \\
0 \\
0\end{array}$ & $\begin{array}{l}8 \\
8 \\
8 \\
0\end{array}$ & \begin{tabular}{l}
8 \\
$\stackrel{8}{\circ}$ \\
\hdashline
\end{tabular} & $\begin{array}{l}8 \\
8 \\
8 \\
0\end{array}$ & $\begin{array}{l}8 \\
8 \\
8\end{array}$ & $\begin{array}{l}8 \\
8 \\
0 \\
0\end{array}$ & $\begin{array}{l}\infty \\
\stackrel{8}{0} \\
0\end{array}$ & $\begin{array}{l}8 \\
\stackrel{8}{8}\end{array}$ & $\begin{array}{l}8 \\
8 \\
0\end{array}$ & $\stackrel{\overrightarrow{8}}{\circ}$ & $\begin{array}{l}8 \\
8 \\
8\end{array}$ & $\begin{array}{l}8 \\
8 \\
8\end{array}$ \\
\hline & 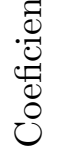 & $\begin{array}{l}\mathscr{8} \\
\stackrel{0}{1} \\
0 \\
1\end{array}$ & $\begin{array}{l}0 \\
0 \\
0 \\
0\end{array}$ & $\begin{array}{l}1 \\
0 \\
0 \\
0\end{array}$ & $\begin{array}{l}- \\
8 \\
0 \\
0 \\
\end{array}$ & $\begin{array}{l}\stackrel{\infty}{二} \\
\underset{F}{F}\end{array}$ & $\underset{\sim}{\stackrel{\sigma}{\sigma}}$ & $\begin{array}{l}\infty \\
\infty \\
0 \\
0\end{array}$ & $\begin{array}{l}0 \\
b 0 \\
0 \\
0 \\
1\end{array}$ & 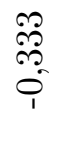 & $\begin{array}{l}10 \\
0 \\
0 \\
0 \\
1\end{array}$ & $\begin{array}{l}\mathscr{8} \\
\mathscr{\delta} \\
0\end{array}$ & $\begin{array}{l}\stackrel{D}{0} \\
0 \\
0\end{array}$ & $\begin{array}{l}0 \\
8 \\
0 \\
0 \\
1\end{array}$ & 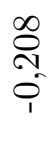 & $\begin{array}{l}\text { तै } \\
\text { Oै } \\
\text { Oे }\end{array}$ & $\begin{array}{l}\infty \\
\infty \\
\infty \\
-1\end{array}$ \\
\hline 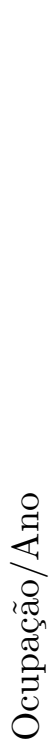 & 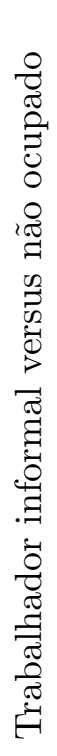 & 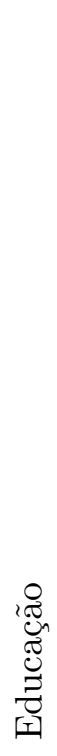 & 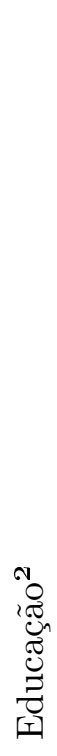 & 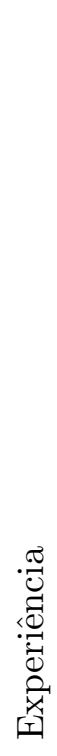 & 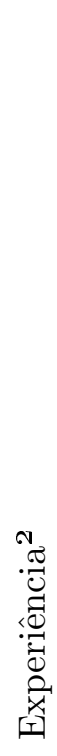 & 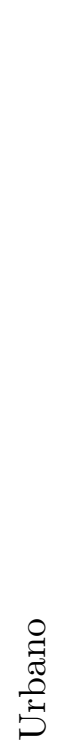 & 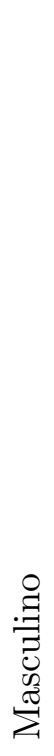 & 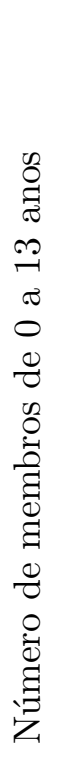 & 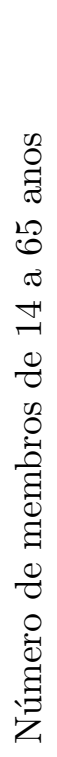 & 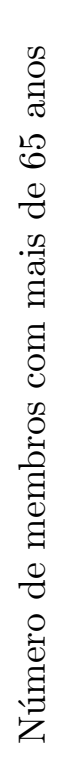 & 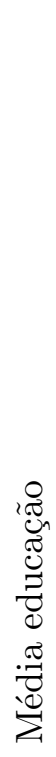 & 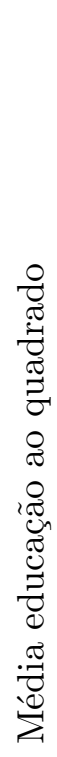 & 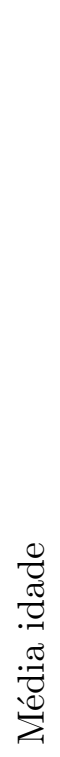 & 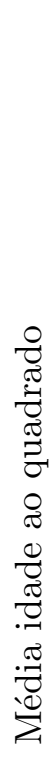 & 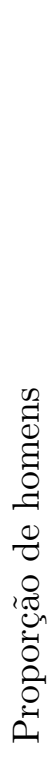 & 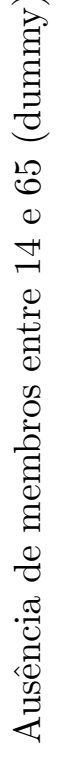 & 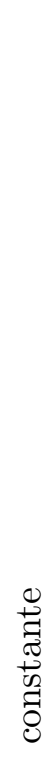 \\
\hline
\end{tabular}




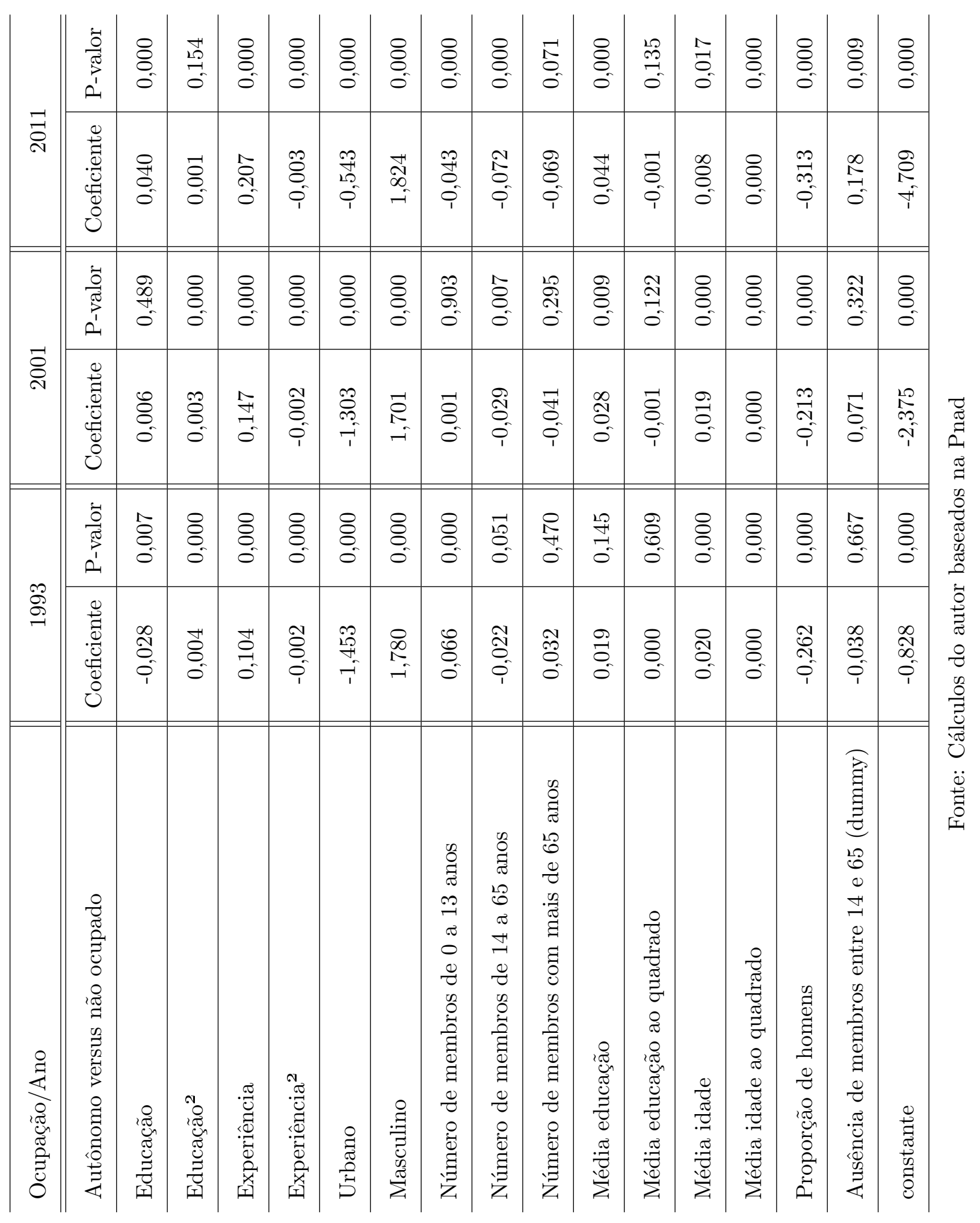




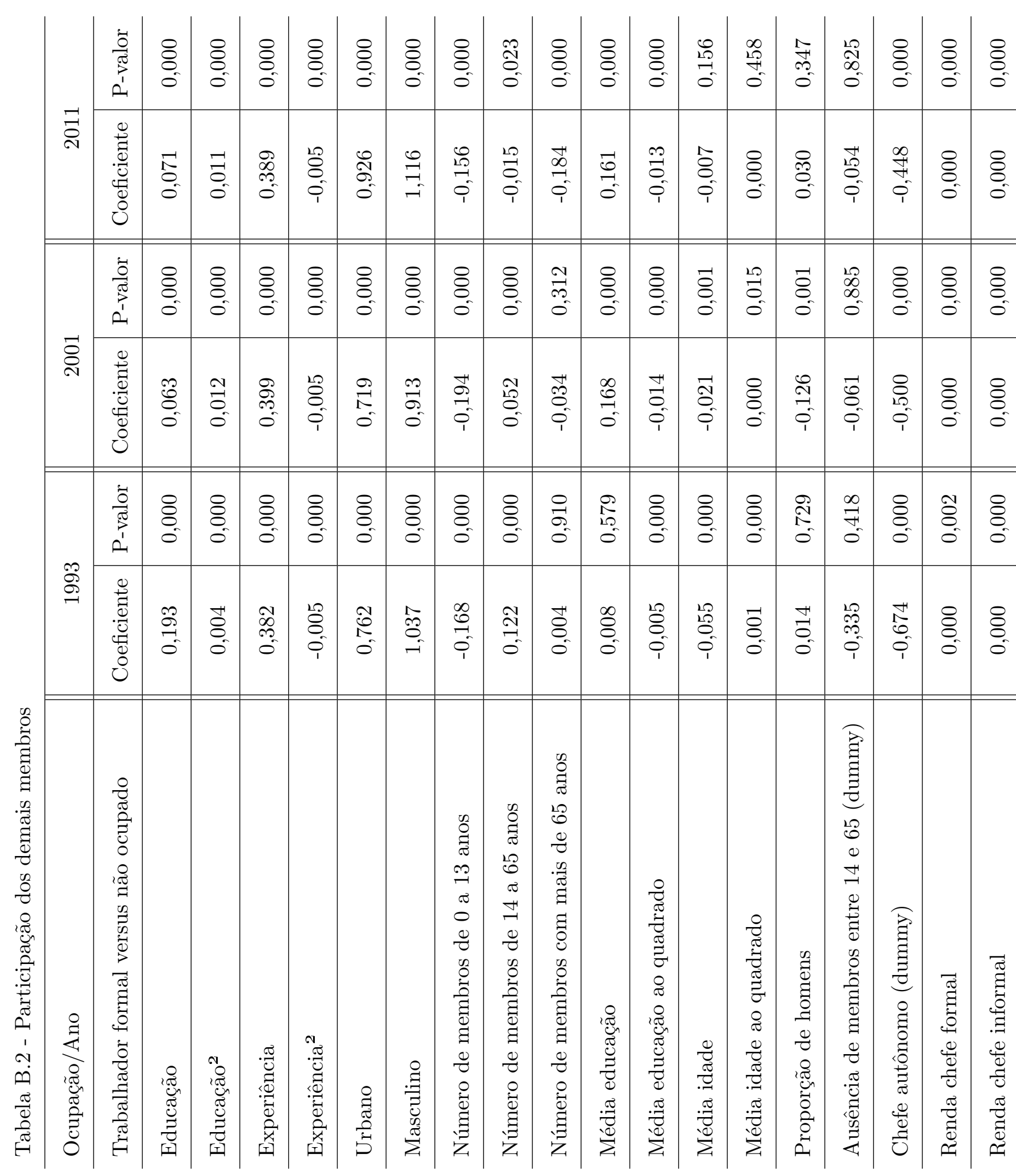




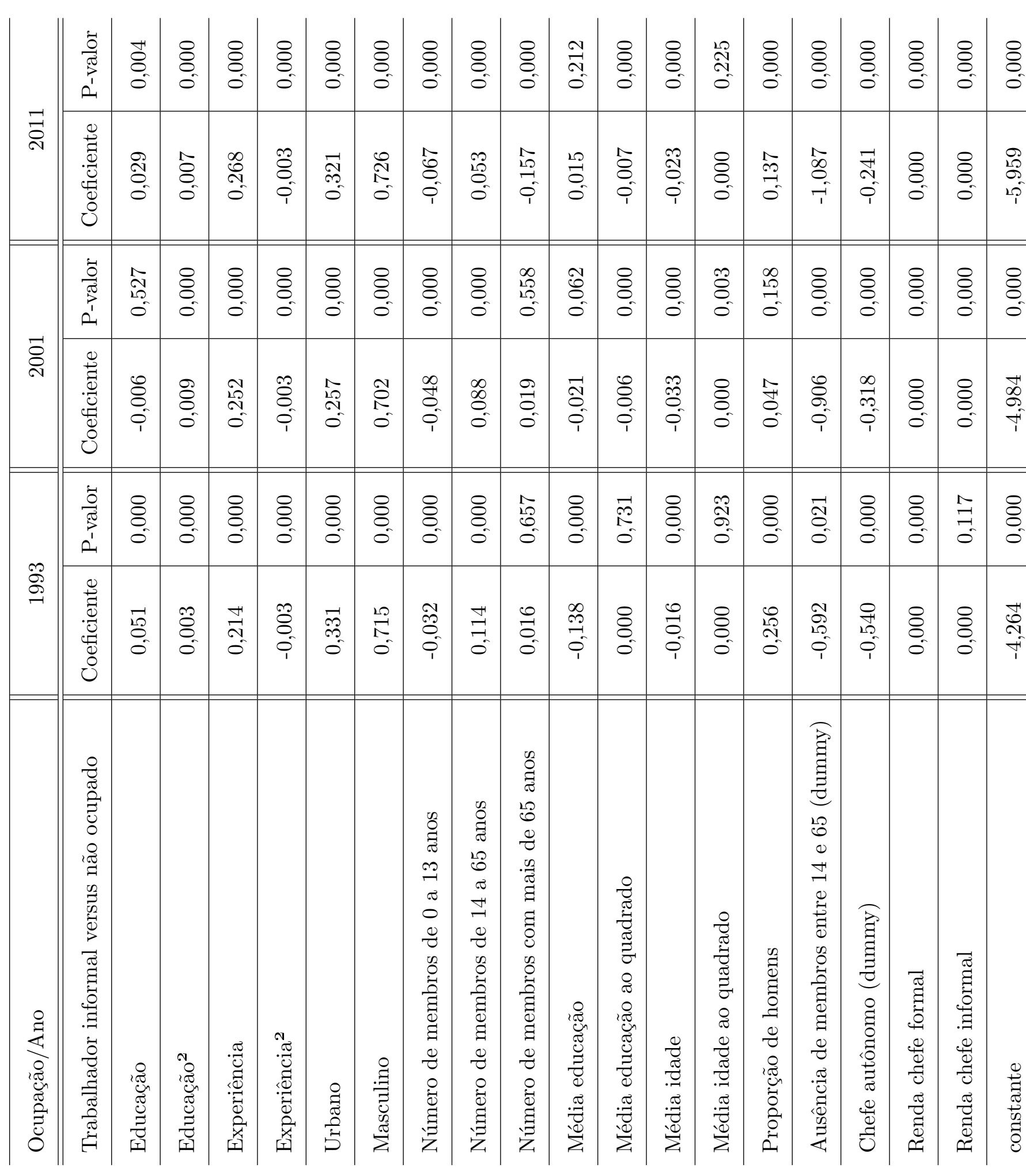




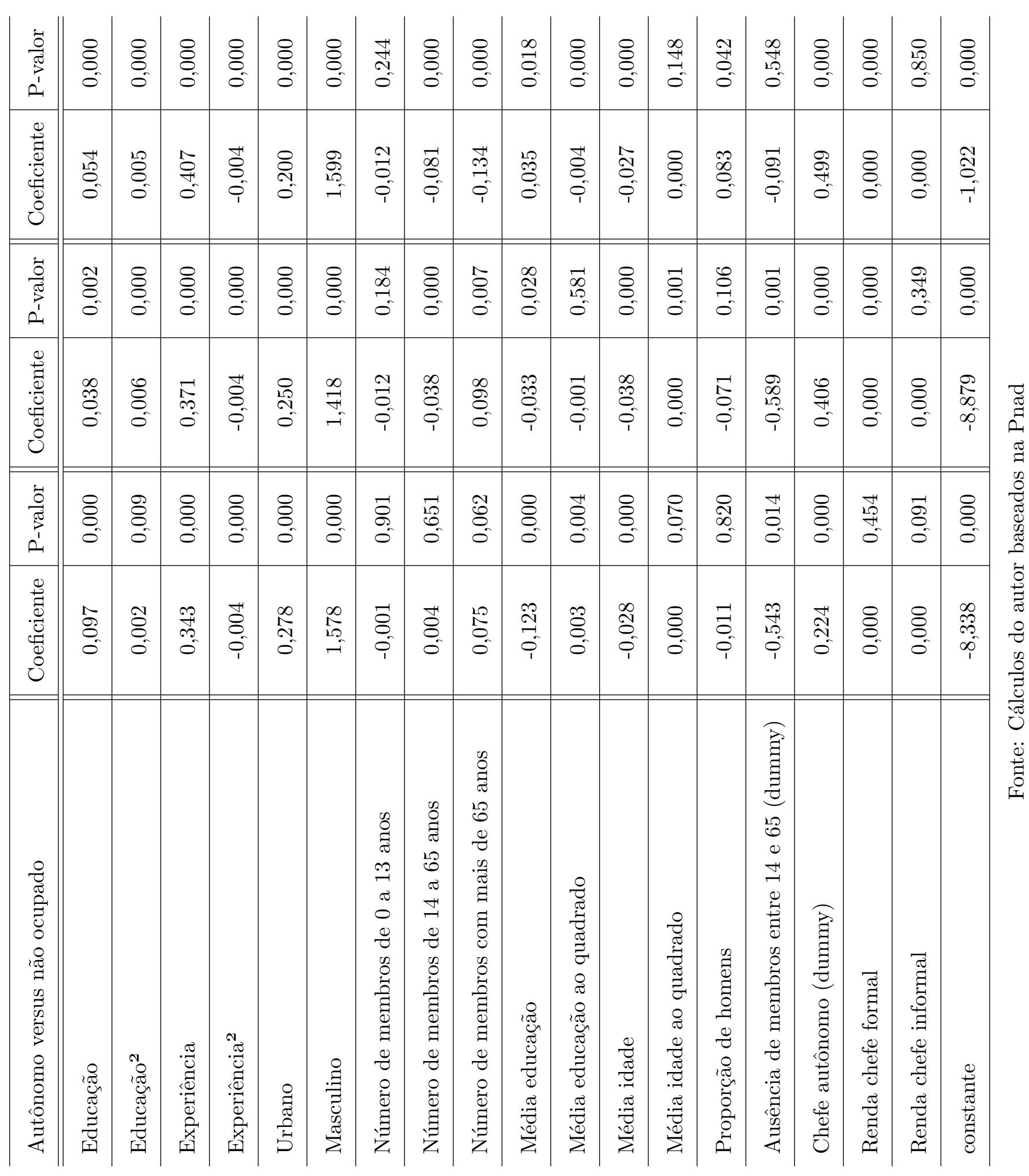




\section{ANEXO}

\section{Anexo A - Linhas de Pobreza e de Extrema Pobreza}

Tabela A.3 - Linhas de Pobreza e de Extrema Pobreza

\begin{tabular}{l||c|c}
\hline Região/Linha de Pobreza & $\begin{array}{c}\text { Pobreza } \\
\text { (em R } \$ \text { de 2012) }\end{array}$ & $\begin{array}{c}\text { Extrema Pobreza } \\
\text { (em R } \$ \text { de 2012) }\end{array}$ \\
\hline \hline Norte & 196,38 & 81,66 \\
\hline Nordeste & 189,33 & 68,36 \\
\hline Sul & 168,03 & 72,92 \\
\hline Centro-Oeste & 257,64 & 75,77 \\
& & \\
\hline Sudeste & & \\
Minas Gerais & 186,68 & 72,59 \\
Espírito Santo & 186,68 & 72,59 \\
Rio de Janeiro & 198,27 & 76,57 \\
São Paulo & 240,86 & 88,63 \\
\hline
\end{tabular}

Fonte: Instituto de Estudos do Trabalho e Sociedade (IETS) 


\section{Anexo B - Cálculo das Linhas de Pobreza e de Extrema Pobreza}

Segue uma breve descrição do método utilizado para calcular as linhas de pobreza e de extrema pobreza adotadas neste estudo.

Segundo a autora, existe consenso na literatura de que, "havendo a disponibilidade de informações sobre a estrutura de consumo das famílias, essa é a fonte mais adequada para o estabelecimento de linhas de pobreza". Uma vantagem para o Brasil é que a riqueza da base de dados estatísticos sobre consumo para o país permite "escolhas e detalhamentos que são relativamente pouco frequentes em outros países". Analisa-se o consumo observado e não adotam-se linhas de pobreza arbitrárias.

A primeira etapa consiste em determinar, para a população em questão, quais são suas necessidades nutricionais. A etapa seguinte objetiva estabelecer, a partir das informações da pesquisa de orçamentos familiares, a cesta alimentar de menor custo que atenda às necessidades nutricionais estimadas. Como não se dispõe de normas que permitam estabelecer qual o consumo mínimo adequado de itens não-alimentares, o valor associado a eles é obtido correspondendo à despesa não-alimentar observada quando o consumo alimentar adequado é atingido.

Mais detalhadamente, as necessidades nutricionais são determinadas da seguinte forma: com base nas recomendações da FAO (Food and Agriculture Organization), diversos autores calculam as necessidades energéticas recomendadas para a população. Afirma-se que a diferença não é muito grande entre as estimativas propostas, então a autora escolhe utilizar Ellwanger (1992). Buscou-se um critério para a definição da cesta alimentar que respeitasse tanto as preferências do consumidor quanto garantisse a ingestão energética recomendada. Assim, toma-se como cesta inicial aquela cesta alimentar que permite atender à chamada "ingestão energética mínima", suficiente apenas para garantir as funções vitais e cujos parâmetros são estabelecidos pela FAO.

Depois, constrói-se uma "cesta ajustada": utilizando as informações da POF, cada cesta de cada localidade é "composta de pelo menos 100 itens que correspondem ao consumo médio diário de alimentos na classe de despesa relevante, isto é, aquela mais baixa onde ocorre adequação em relação à necessidade energética mínima". Excluíram-se itens alimentares que representassem uma ingestão inferior a uma caloria por dia. 
Essas cestas alimentares reduzidas tiveram suas quantidades de cada produto ajustadas proporcionalmente de modo a corresponder à ingestão calórica recomendada em cada região metropolitana". A atualização dos preços para setembro de cada ano, que é o mês de referência da Pnad, foi realizada a partir do INPC (Índice Nacional de Preços ao Consumidor) - alimentação do IBGE.

A definição do consumo não-alimentar mínimo não possui uma base teórica. "O procedimento apresentado toma por base a classe de renda das famílias para a qual as necessidades energéticas mínimas foram atingidas, classificando as despesas não-alimentares correspondentes de acordo com seis categorias de produtos" (habitação, artigos de residência, vestuário, comunicação/transporte, saúde/cuidados pessoais e despesas pessoais). Portanto, os valores aqui calculados não consideram o coeficiente de Engel (despesa alimentar sobre despesa total). Os valores são atualizados por índices de preços correspondentes para caga grupo de gasto e região.

A linha de pobreza é a soma dos dois valores: cesta alimentar e outras despesas. O cálculo é realizado para 24 áreas no país. Vale ressaltar que para regiões não-metropolitanas utilizamse informações sobre consumo e preço do Estudo Nacional da Despesa Familiar (Endef) calculados por Fava (1984). 